\title{
Loquacious Modulates Flaviviral RNA Replication in Mosquito Cells
}

1 Department of Microbiology \& Immunology, Stanford University SOM, Stanford, CA 94305,

7 USA, 2 Stanford ChEM-H, Stanford, CA 94305,

8

$9 \quad{ }^{*}$ Corresponding author:

10 Peter Sarnow

11 Dept. of Microbiology \& Immunology

12 Stanford University School of Medicine

13 Stanford, CA 94305, USA

14 psarnow@stanford.edu

15

16 Present addresses:

$17{ }^{3}$ Duke-NUS Medical School

188 College Road

19 Singapore 169857

20

$21{ }^{4}$ Stem Cell Program, Boston Children's Hospital, Boston, MA. Department of Stem Cell and

22 Regenerative Biology, Harvard University, Cambridge, MA 02138, USA 


\section{Abstract}

Arthropod-borne viruses infect both mosquito and mammalian hosts. While much is known about virus-host interactions that modulate viral gene expression in their mammalian host, much less is known about the interactions that involve inhibition, subversion or avoidance strategies in

28 the mosquito host. A novel RNA-Protein interaction detection assay was used to detect proteins

29 that directly or indirectly bind to dengue viral genomes in infected mosquito cells. Membrane-

30 associated mosquito proteins SEC61A1 and Loquacious (Loqs) were found to be in complex

31 with the viral RNA. Depletion analysis demonstrated that both SEC61A1 and Loqs have pro-

32 viral functions in the dengue viral infectious cycle. Co-localization and pull-down assays showed

33 that Loqs interacts with viral protein NS3 and both full-length and subgenomic viral RNAs. While

34 Loqs coats the entire positive-stranded viral RNA, it binds selectively to the 3' end of the

35 negative-strand of the viral genome. In-depth analyses showed that the absence of Loqs did not

36 affect translation or turnover of the viral RNA but modulated viral replication. Loqs also

37 displayed pro-viral functions for several flaviviruses in infected mosquito cells, suggesting a

38 conserved role for Loqs in flavivirus-infected mosquito cells.

\section{Author Summary}

42 There is a wealth of information that dictates virus-host interactions in flavivirus-infected

43 mammalian cells, yet there is only sparse information on the mechanisms that modulate viral

44 gene expression in the mosquito host. Using a novel RNA-protein detection assay, the

45 interactions of SEC61A1 and Loqs with the dengue viral genome were found to have proviral

46 functions in infected mosquito cells. In particular, Loqs forms complexes with the positive-strand

47 of the viral RNA and the very 3' end of the negative-strand viral RNA. Further analyses showed

48 that Loqs modulates viral RNA replication of dengue virus and gene amplification of several 
other flaviviral genomes. These findings argue that Loqs is an essential proviral host factor in

50 mosquitos.

\section{Introduction}

Dengue virus (DENV) is an enveloped, single-stranded positive sense RNA virus belonging to

55 the Flaviviridae family. It infects $\sim 400$ million people worldwide every year and is transmitted by

56 the Aedes aegypti and Aedes albopictus species of mosquitoes [1]. The $\sim 11 \mathrm{~kb}$ DENV genomic

57 RNA consists of an open reading frame that codes for the structural and nonstructural viral

58 proteins, flanked by 5' and 3' untranslated regions (UTR) (Fig. 1A). The viral UTRs are involved

59 in multiple RNA-RNA and RNA-protein interactions that regulate the efficiency of infection,

60 modulate host innate immune responses and viral pathogenesis [2, 3].

62 The interactions of the DENV 3'UTR with viral and host cellular proteins are particularly

63 interesting because of the diverse roles of the 3'UTR in viral infection. First, it is the site of

64 initiation of viral RNA replication. Secondly, it is a hotspot for accumulation of adaptive

65 mutations in both human and mosquito hosts. Third, it is resistant to degradation by host

66 exoribonuclease XRN1, which allows subgenomic flaviviral RNAs (sfRNAs) to accumulate (Fig

67 1A) [4-6]. Biochemical methods such as RNA-affinity capture have identified several human

68 proteins in complexes with the 3' end of DENV genomic RNA or sfRNAs to regulate viral

69 replication and immune evasion [7-11]. A recent study used ChIRP-MS (Comprehensive

70 Identification of RNA Binding Proteins by Mass spectrometry), an intracellular crosslinking

71 approach to identify numerous RNA binding proteins that interact directly with the DENV RNA in

72 mammalian cells [12]. Specifically, the endoplasmic reticulum-associated proteins vigilin and

73 ribosome-binding protein 1 (RRBP1) were associated with DENV RNA, and modulated viral

74 RNA replication and translation, respectively [8]. 
76 While most studies have focused on viral RNA-host protein interactions in mammalian cells,

77 there has been less investigation of proteins that form complexes with the DENV RNA and

78 regulate infection in mosquito cells [3]. In this study, we have employed an intracellular

79 biotinylation-based approach called RaPID (RNA-Protein Interaction Detection)[13] to identify

80 mosquito proteins that form complexes with the DENV 3'UTR in mosquito cells. While this

81 technique has been previously used to identify proteins that bind to Zika virus and rotavirus in

82 mammalian cells $[14,15]$, adaptation to mosquito cells has allowed us to identify critical

83 regulators of DENV replication in the mosquito host.

Results

Biotinylation-based proteome analysis identifies DENV 3'UTR-protein interactions in mosquito cells

89 We designed the RaPID system to identify proteins that interact with the dengue viral (New

90 Guinea strain DENV2-NGC, DENV) 3'UTR (Fig. 1A,B) in mosquito cells. A 271 nucleotide (nt)

91 region at the 3' end of the DENV 3'UTR (184-454 nts) was chosen as a target as it is present

92 both in the genomic RNA as well as the subgenomic RNA fragments, sfRNA3 and sfRNA4,

93 which specifically accumulate in mosquito cells during infection with mosquito-adapted DENV

94 RNA, whereas sfRNAs1/2 predominately accumulate in infected human cells [6, 16]. Briefly, the

95 target DENV RNA sequence, encompassing sfRNAs 3/4 (Fig. 1A), was expressed within

96 flanking phage $\lambda N$-BoxB RNA motifs, together with a fusion protein composed of biotin ligase

97 and the $\lambda \mathrm{N}-$ BoxB RNA binding protein in mosquito cells (Fig. 1B). In the presence of biotin, the

$98 \lambda \mathrm{N}$-biotin ligase is expected to bind with the BoxB RNA stem loops and biotinylate proteins that

99 bind directly or are in a complex with the target DENV RNA sequence. Biotinylated proteins can 
then be isolated using streptavidin beads and identified by mass spectrometry (LC-MS/MS)

(Fig. 1B).

103 In a proof-of-principle experiment, we tested whether RaPID could detect the known RNA-

104 protein complex between the EDEN15 RNA motif and ELAV family of proteins [15] in mosquito

105 C6/36 cells. C6/36 cells were co-transfected with plasmids expressing the EDEN15-BoxB RNA

106 (Fig. 1C) and the $\lambda \mathrm{N}$-biotin ligase protein. As a negative control, cells were co-transfected with

107 plasmids expressing a scrambled EDEN15 sequence and the $\lambda \mathrm{N}$-biotin ligase protein.

108 Biotinylated proteins were isolated using streptavidin beads and the peptides were identified by

109 LC-MS/MS. Results were filtered and peptides that were enriched at the EDEN15 motif with a

110 probability score (SAINT score) of greater than 0.9 relative to the scrambled sequence were

111 shortlisted as true binders (Table S1). We identified the mosquito ELAV protein, a homolog of

112 human CELF1 to be 40 -times enriched in the EDEN15 expressing cells relative to the

113 scrambled sequence, suggesting an interaction of the ELAV protein with the EDEN15 RNA (Fig.

114 1E). This experiment confirmed that the RaPID pipeline works efficiently in mosquito cells.

116 Next, we expressed the DENV 3' UTR-BoxB RNA (Fig 1D) and the $\lambda N$-biotin ligase protein in

117 mosquito cells. RaPID analysis (Table S1) identified two high confidence hits (Fig.1F) that could

118 potentially interact with this region of the DENV 3'UTR in mosquito cells: AAEL010716 is an

119 unannotated gene in mosquitoes, but is $90 \%$ identical to the Drosophila endoplasmic reticulum

120 transport protein Sec61 subunit alpha (Sec61A1) [17]. AAEL008687 (Loquacious, Loqs)

121 encodes a dsRNA-binding protein Loqs. Curiously the Loqs-PA isoform is involved in the RNAi

122 immune response pathway in mosquitos [18]. Sec61A1 is known to play a proviral role in

123 flaviviral infection in both human and mosquito cells by modulating viral mRNA translation [19].

124 However, no role for Loqs in viral infection has been suspected. In addition, RaPID identified 
125 AOA182HDU4 encoding ATX2, which displays 24\% identity to human ATX2. ATX2 has been

126 shown to bind to several DEAD box RNA helicases, which are known to be involved in RNA

127 processing pathways both in mosquitos and humans [20, 21]. However, ATX2 was enriched

128 with a slightly lower SAINT probability score of 0.736 (Fig. 1F). We chose to pursue the

129 potentially novel roles for Sec61A1 and Loqs in DENV-infected mosquito cells.

\section{Partial depletion of Sec61A or Loqs inhibits DENV replication in mosquito cells}

132 To determine the effects of Sec61A1 and Loqs on DENV RNA expression, mRNAs encoding

133 these proteins were depleted in infected cells. Because C6/36 cells are deficient in the RNAi

134 pathway [22], RNAi-competent Aag2 mosquito cells [23] were used in the mRNA depletion

135 assays. Loqs has two abundant isoforms in mosquito cells, Loqs-PA and Loqs-PB. Thus, dsRNAs were designed to target both isoforms (dsLoqs) or only the Loqs-PB isoform (dsLoqs-

137 PB), which can be selectively targeted due to the presence of a unique exon 5. Aag2 cells were

138 transfected with 500bp long double-stranded RNAs targeting Sec61A1 or Loqs mRNAs.

139 Transfected cells were subsequently infected with the DENV2- New Guinea C strain (NGC) at a

140 multiplicity of infection (MOI) of 0.1 . At $96 \mathrm{hrs}$ post infection, cells were harvested and

141 processed for downstream assays (Fig. 2A).

143 Efficiencies of Sec61A1 and Loqs mRNA depletions were demonstrated by measuring the

144 individual mRNA abundances by qPCR (Fig. S1A). Depletion of specific isoform proteins of

145 Loqs was also validated by western blot analysis (Fig. S1B). RT-PCR analysis revealed a 146 significant reduction in DENV RNA abundances upon depletion of either Sec61A1 or Loqs

147 mRNAs (Fig. 2B). Depleting both isoforms of Loqs (dsLoqs) had a greater effect on viral RNA 148 levels than depleting just the PB isoform (dsLoqs-PB), suggesting that Loqs-PA might play a 149 more predominant role in supporting viral infection (Fig. 2B). Northern blot analysis using 150 probes against the DENV 3'UTR indicated a reduction of both DENV genomic RNA and sfRNA 
151 abundances in Sec61A1 and Loqs depleted cells relative to the control dsGFP-treated cells

152 (Fig. 2C). Depletion of Sec61A1/Loqs also resulted in a significant reduction in DENV NS3

153 protein abundance (Fig. 2D). Finally, plaque assays indicated a significant hundred-fold

154 reduction in the viral titer in both dsSec61A1- and dsLoqs-treated cells (Fig. 2E). These data

155 argue that both Sec61A1 and Loqs have pro-viral functions in DENV-infected mosquito cells.

157 To examine whether the observed effects were specific to DENV2-NGC, mRNA depletion

158 experiments were repeated in cells infected with Thailand strain DENV2-16681, which has

159 distinct mutations from the DENV2-NGC virus [24]. Results in Fig. S1C showed that depletion of

160 SEC61A1 or Loqs also diminished DENV2-16681 RNA abundances. Similarly, a reduction in

161 both extracellular (Fig. S1D) and intracellular (Fig. S1E) viral RNA abundances was observed

162 after depletion of SEC61A1 or Loqs, arguing that that both proteins have pro-viral functions in

163 the infectious cycle in both DENV2-NGC and DENV2-16681 infected cells.

165 In order to rule out any non-specific effects associated with using dsRNAs, which are processed

166 into multiple siRNAs, we designed individual siRNAs targeting either Sec61A1 or Loqs mRNAs.

167 A significant reduction in DENV RNA levels in Sec61A1- and Loqs- siRNA-treated cells was

168 observed relative to the non-targeting control siRNA treated cells (Fig S2A). Because it is

169 unlikely that all siRNAs have the same off-target effect, this data argues that dsRNAs

170 specifically depleted SEC61A1 and Loqs mRNAs. To rescue the phenotype observed after

171 depletion of SEC61A1 and Loqs, we expressed Loqs-PA and Loqs-PB encoding cDNAs in cells

172 treated with siRNAs targeting the 3'UTR of endogenous Loqs. However, no rescue of the

173 siLoqs-induced phenotype was observed (Fig. S2B). Unfortunately, we were also unable to

174 express the full length Sec61A1 protein in our rescue studies. 
176 To test if these host proteins are essential in the infectious cycles of other RNA viruses,

177 Sec61A1 and Loqs- depleted Aag2 cells were infected with West Nile virus (WNV), yellow fever

178 virus (YFV), Zika virus (ZIKV) or Chikungunya virus (CHIKV). A significant reduction in YFV and

179 ZIKV RNA abundances were observed after depletion of either of these two proteins (Fig. 3). In

180 case of WNV, depletion of Sec61A1 affected viral RNA abundances, while depletion of Loqs

181 had no effect (Fig. 3). Surprisingly, depletion of either of the two proteins resulted in an increase

182 in CHIKV RNA abundances, a virus which belongs to the Togaviridae family. These

183 experiments suggest that Sec61A1 and Loqs play a proviral role in the infectious cycle of

184 several flaviviruses, but can play antiviral roles as well, as is often seen in the battle between

185 viruses and their hosts. Next, we focused on characterizing the role of Loqs in viral infection in

186 more detail.

\section{Loqs colocalizes and forms complexes with DENV RNA in infected mosquito cells}

189 The RaPID approach suggested that Loqs directly or indirectly binds to the DENV

190 genomic/subgenomic RNA sequences. To test if Loqs co-localizes with the genomic DENV RNA

191 in infected cells, in situ hybridization experiments were carried out in DENV-infected Aag2 cells.

192 Immunostaining for endogenous Loqs protein showed that it is predominantly located in the

193 cytoplasm in infected cells (Fig. 4A). DENV RNA was visualized by in situ RNA hybridization,

194 using fluorescently labeled probes directed against viral NS5 region, which also localized to the

195 cytoplasm. To examine whether Loqs and DENV RNA significantly colocalized, images were

196 analyzed by Color 2, an algorithm for measuring colocalization in pixel images, and the

197 significance of colocalizations was determined by the Costes P-value [25]. The results showed

198 that Loqs protein and DENV RNA significantly colocalized with each other (Costes P-value >

$1990.95)$ in $80 \%(28 / 35)$ of the analyzed infected (DENV RNA positive) cells (Fig 4A, lower

200 panels). In comparison, the known colocalization of DENV NS3 protein with DENV RNAs [26] 
was $97 \%(34 / 35)$ of the inspected cells. These results suggest that Loqs colocalizes with DENV RNAs with a significance that is comparable to that of DENV RNA-NS3 colocalization.

To detect Loqs protein-DENV RNA complexes by immunoprecipitation, Aag2 cells were

205 transfected with HA-tagged Loqs PA or HA-EGFP and subsequently infected with DENV

206 infection. HA-tagged proteins were immunoprecipitated (Fig. 4B) and DENV RNA was detected

207 by semi-quantitative PCR (Fig 4C) and qPCR (Fig 4D). A significant enrichment of DENV RNA

208 was observed upon HA-Loqs immunoprecipitation as compared to the control

209 immunoprecipitations. Northern blot analysis showed that Loqs binds both to the full-length

210 DENV RNA and to sfRNAs, relative to the $\lg$ G control (Fig. S3A). To pinpoint the region on the

211 viral RNA where Loqs binds, we performed infrared crosslinking and immunoprecipitation

212 (irCLIP) assays [13] in infected cells expressing HA-Loqs. Reverse transcriptase stops for Loqs

213 were mapped across the full-length viral RNA including the UTRs (Fig. S3B). The results

214 showed that Loqs interacted with the entire positive-stranded viral RNA, with a few dozen hot

215 spots. However, Loqs poorly interacted with the negative-stranded viral RNA with an

216 exceptional single specific band at the very 3' end of the negative strand (Fig. S3C). These

217 findings show that Loqs can coat the entire positive-strand viral RNA, possibly by its relative

218 accessibility.

220 Loqs modulates DENV RNA replication

221 Because Loqs supports viral infection and interacts with DENV RNA, we tested whether Loqs

222 affects translation, replication or stability of the viral RNA. First, we tested if Loqs is associated

223 with the endoplasmic reticulum (ER), which is the primary site for DENV RNA translation and

224 replication. A digitonin-based fractionation method was employed to separate the cytoplasmic

225 and membrane-associated proteins and to determine the localization of Loqs by western blot

226 analysis. Both Loqs-PA and Loqs-PB were enriched in the membrane fractions in both 
227 uninfected and infected cells (Fig. 5A), as was the DENV NS3 protein in infected cells. Next, the

228 association of Loqs with replication proteins NS3, NS5, NS4B and the viral capsid proteins were

229 studied. Immunoprecipitation of HA-tagged Loqs-PA from infected Aag2 cells indicated complex

230 formation with only NS3 protein (Fig. 5B), which is essential for both viral RNA translation and

231 replication [26]. This complex formed with or without RNAse treatment (Fig. 5B). These findings

232 argue that Loqs is specifically associated with NS3 in membranes in infected cells.

234 To test if Loqs depletion affects viral RNA translation, the association of DENV RNA with

235 polysomes in infected cells was examined. The abundance of DENV RNA in each individual

236 fraction from cells treated with dsGFP or dsLoqs RNAs, was analyzed by qPCR (Fig. S4).

237 DENV RNA was distributed in fractions 8 through 14 in both wildtype and Loqs-depleted cells

238 suggesting that Loqs doesn't affect the association of ribosomes with viral RNA, and the

239 association of multiple ribosomes with individual RNAs (Fig. S4) argues that translation

240 elongation is also not blocked when Loqs is depleted.

242 To examine effects of Loqs on viral RNA translation and replication in more detail, expression of

243 luciferase-containing wildtype and replication-defective replicon RNAs were examined in Loqs-

244 depleted C6/36 cells. C6/36 cells were used in this experiment as they were able to better

245 support replicon expression as compared to Aag2 cells. The accumulation of viral RNA is

246 affected by both its synthesis and degradation. We observed a one-log reduction in luciferase

247 expression from the wildtype replicon in Loqs siRNA-transfected cells (Fig. 5C). However, there

248 was no difference in luciferase expression from the replication-defective mutant in Loqs siRNA-

249 treated cells (Fig. 5C), suggesting that Loqs primarily affects viral RNA replication rather than

250 RNA translation. Furthermore, this result also confirms that the Loqs siRNAs did not display off-

251 target effects on the viral genome. 
253 The rate of degradation of DENV RNA in siLoqs-treated cells was examined after addition of the

254 NS5 RNA polymerase inhibitor 2'-C-methyladenosine (2'CMA) [27, 28]. C6/36 cells were

255 transfected with siRNAs, infected with DENV and viral RNA abundances were measured by

256 qPCR. There was no significant difference in the rate of degradation of viral RNA in Loqs

257 siRNA-treated DENV2 infected cells compared to the control siRNA-treated cells indicating that

258 Loqs doesn't affect viral RNA degradation (Fig. 5D). These experiments point towards a role for

259 Loqs in DENV RNA replication, but not viral RNA stability.

\section{Effects of Loqs on DENV replication is independent of its role in the RNAi pathway}

262 It is known that Loqs interacts with Dicer and Argonaute proteins to regulate both siRNA and

263 miRNA pathways in mosquito cells [18]. Thus, we investigated whether Loqs could bind to the

264 viral RNA and possibly protect the viral genome from siRNA or miRNA mediated degradation.

265 To test this hypothesis, Dicer-2 KO Aag2 cells (AF319) cells [29] were treated with siRNAs

266 directed against Sec61A1 or Loqs and transfected with infectious DENV-luciferase virus (Fig.

267 S5A) or DENV-luciferase replicon RNAs (Fig. S5B). Depletion of Loqs in AF319 cells also

268 resulted in a significant reduction of luciferase expression from DENV full length or replicon

269 RNAs, suggesting that Loqs regulation of DENV replication is independent of Dicer-2.

272 Discussion:

274 Interactions of RNA viral genomes with host RNA binding proteins are essential for viral

275 infection and immune evasion in both human and mosquito hosts. Host RNA-binding proteins

276 interactions with viral RNA can result in structural and/or functional changes that can be either

277 restrictive or supportive of viral infection. A recent ChIRP-MS screen identified RRBP and vigilin

278 as DENV RNA binding proteins that support viral RNA translation, replication and stability [12]. 
279 In addition, the DENV 3'UTR is known to interact with and co-opt DDX6 and Lsm1 proteins to

280 support viral RNA replication while other 3'UTR interacting proteins such as Quaking (QKI) play

281 antiviral roles and inhibit DENV RNA replication $[8,9]$.

282

283 In addition to the DENV genomic RNA, DENV sfRNAs derived from the 3'UTR can also form

284 complexes with host proteins to modulate viral transmission and immune evasion. For example,

285 sequestration of TRIM25, G3BP and Caprin proteins by DENV sfRNAs suppresses antiviral

286 interferon responses in mammalian cells while sfRNA interactions with Dicer and Ago2 proteins

287 suppresses antiviral RNAi response in both mammalian and mosquito cells [10, 11]. A recent

288 study showed that sequestration of the mosquito antiviral proteins ME31B, ATX2 and

289 AAEL018126 by ZIKV and WNV sfRNAs increases viral transmission in mosquitoes [30].

291 Furthermore, viruses can target host RNA-binding proteins to modulate viral gene amplification.

292 Our study identified Sec61A1 and Loquacious as proteins that interact with the DENV 3'UTR in

293 mosquito cells. While several proteins associated with the ER have been shown to be critically

294 important for viral replication in mammalian cells, the exact mechanism by which they regulate

295 viral infection is unknown. Sec61A and Sec61B have been predicted to have non-canonical

296 RNA binding activity, which could help in transporting the viral RNA to the ER for

297 translation/replication [31, 32]. The identification of mosquito Sec61A1 in our RAPID screen

298 suggests a possible direct interaction between Sec61A1 and the viral RNA which could

299 influence viral RNA localization and/or replication.

301 We observed that Loqs colocalizes with NS3 in membranous fractions in DENV-infected

302 mosquito cells and interacts with both DENV genomic and subgenomic RNAs. The lack of

303 obvious hydrophobic or transmembrane regions in the protein suggests that Loqs could be

304 anchored to the membranes by other membrane-associated host or viral proteins. The 
membrane localization of Loqs puts it at a strategic position to support viral translation and replication which occur in ER-derived membranous scaffolds. Because we did not observe any obvious effects of Loqs depletion on polysome association of the DENV RNA or luciferase expression from a non-replicating DENV replicon, we conclude that Loqs predominantly affects viral RNA replication. Because the stability of DENV RNA was not affected in Loqs-depleted cells, we hypothesize that Loqs regulates the efficiency of viral RNA replication.

312 The interaction of Loqs with DENV genomic RNA and viral protein NS3 suggests that Loqs can

313 modulate the viral replication machinery. The enhanced binding of Loqs at the 3' end of the viral

314 negative strand may indicate a role for Loqs in the synthesis of positive viral RNA strands.

315 However, the significance of the interaction of Loqs with sfRNAs is less clear. Alternatively, the

316 relative affinity of Loqs for sfRNAs could be different than that for the genomic RNA, and these

317 affinities may dictate distinct steps in the viral infectious cycle.

Loquacious is known to interact with R2D2, Ago2 and Dicer1/2 proteins to regulate siRNA and miRNA biogenesis [18]. While the mosquito midgut expresses isoforms that interact

321 predominantly with Dicer to regulate siRNA generation and miRNA production, our experiments

322 with Dicer-depleted cultured cells suggest that the pro-viral effects of Loqs is independent of any

323 effects on small RNA biogenesis. A study showed that ectopic expression of Loqs2, a paralog of

324 Loqs, inhibits systemic dissemination of DENV in in Aedes aegypti mosquitos by engaging the

325 antiviral RNAi pathway [33]. The study also predicted a possible interaction between Loqs2 and

326 Loqs in mediating this antiviral phenotype. In our study, we were unable to detect the

327 endogenous Loqs2 mRNA in Aag2 cells. However, it is possible that Loqs is recruited by DENV

328 to play a proviral role in tissues like the midgut where antiviral functions of the RNAi pathway

329 are compromised. Future experiments that dissect the role of the RNAi pathway on viral

330 replication in $\mathrm{C} 3 / 36$ and immuno-competent Aag2 cultured cells, and in different mosquito 
331 tissues will reveal the roles for canonical and non-canonical RNA binding proteins on flaviviral

332 gene expression in the mosquito host.

\section{Materials and methods}

\section{Cell culture}

Huh7 and BHK21 cells were cultured as monolayers in Dulbecco's modified Eagle's medium.

340 Aedes albopictus C6/36 cells and Aedes aegypti Aag2 cells were cultured as monolayers in

341 Leibovitz's L-15 and Schneider's Drosophila media, respectively. All culture media were

342 supplemented with $10 \%$ fetal bovine serum, 100 units of penicillin $/ \mathrm{ml}, 100 \mu \mathrm{g}$ of streptomycin $/ \mathrm{ml}$,

$34310 \mathrm{mM}$ HEPES ( $\mathrm{pH}$ 7.2), 1X NEAA (non-essential amino acid medium) and 2mM L-Glutamine

344 (Gibco). Mammalian cell lines were grown at $37^{\circ} \mathrm{C}$ with $5 \% \mathrm{CO}_{2}$, and insect cell lines were

345 grown at $30^{\circ} \mathrm{C}$ without $\mathrm{CO}_{2}$. The Dicer2-knockout AF319 cell line was a kind gift from Dr. Kevin

346 Maringer (The Pirbright Institute,UK).

348 Plasmids

350 Plasmids pKF, pKF_EDEN15 and pKF_Scr containing BoxB stem loop sequences

351 (GCCCTGAAAAAGGGC) flanking t3 repeats of the EDEN15

352 (TGTTTGTTTGTTTGTTGTTTGTTTGTTTGTTGTTTGTTTGTTTGT) or Scrambled EDEN15

353 (TTTTTGTTTTTTGGTTGTGGTTTTTTTTGTTGGGTTGGTTTTTTT) sequences and the BASU

354 plasmid expressing the $\lambda \mathrm{N}$-biotin ligase fusion protein were a kind gift by Dr. Paul Khavari

355 (Stanford University). A region of the DENV 3'UTR corresponding to sfRNA3 (271-455bp) was

356 amplified from the DENV2-16681 cDNA and cloned in between BoxB sequences of pKF by 
357 Gibson assembly. The entire region containing GFP-BoxB-RNA of interest-BoxB-WPRE from 358 pKF was subcloned into pBG34 (a kind gift from Dr. Brian Geiss, Colorado State University) by 359 infusion cloning for expression in mosquito cells. The BG34-DENV 3'UTR clones used for

360 RaPID experiments contain 2 BoxB sequences at the 5' end and 3 BoxB sequences at the 3' 361 end of the DENV 3'UTR. The BG34-EDEN15 and BG34-Scr plasmids contain 3 flanking BoxB 362 sequences both at their 5' and 3' ends. FLAG-tagged and HA-tagged pUB-Loqs and pUB-Loqs-

363 PB plasmids were a kind gift by Dr. Zachary Adelman (Texas A\&M University). EGFP was

364 cloned into Ndel and Sall sites of the pUB vector to express HA-tagged GFP. The DENV2- New

365 Guinea C strain and the DENV2-16681 luciferase reporter replicons were a kind gift by Dr. Jan

366 Carette (Stanford University). Primers used in this study are listed in Table S2.

\section{In vitro RNA transcription}

Dengue virus 2 serotype 16681 was propagated from infectious cDNA clone pD2IC/30P-A, a gift

372 containing plasmids were linearized by digestion with Xbal and in vitro transcriptions were

373 performed using the MEGAscript T7 transcription kit (AM1334). 5mg of the Xbal-linearized

374 plasmid was incubated with $1.3 \mathrm{ml}$ of $75 \mathrm{mM}$ rATP, $6.7 \mathrm{ml}$ each of $75 \mathrm{mM} \mathrm{rCTP}$, rGTP and rUTP,

$37510 \mathrm{ml}$ of $10 \mathrm{X}$ reaction buffer, $10 \mathrm{ml}$ of $\mathrm{T} 7$ enzyme mix and $12.5 \mathrm{ml}$ of 5'GpppA cap analog

376 (S1406S, NEB) in a final reaction volume of $100 \mathrm{ml}$ for $30 \mathrm{~min}$ at $30^{\circ} \mathrm{C} .2 .6 \mathrm{ml}$ of $75 \mathrm{mM}$ rATP

377 was added to the reaction and further incubated for $4 \mathrm{hrs}$ at $30^{\circ} \mathrm{C}$. The reactions were treated

378 with DNAse, and RNA was purified using the RNEasy mini kit (Qiagen) according to

379 manufacturer's protocol. 
384 In vitro transcribed capped DENV2 RNA was transfected into BHK21 cells in 24 well plates.

385 Supernatants were collected $48 \mathrm{hrs}$ post transfection and used to infect C6/36 cells overnight in 386 a T75 flask containing $3 \mathrm{ml}$ complete medium. $15 \mathrm{ml}$ of complete medium was added to the flask 387 the next day and virus supernatant was collected 6 days post infection. DENV2-NGC stocks 388 were prepared similarly by infecting C6/36 cells in medium containing $2 \%$ FBS and HEPES.

389 Viruses were titered on BHK21 cells to calculate PFU/ml. Virus infections were carried out by 390 incubating cells with virus at the desired MOI for $1.5 \mathrm{hrs}$ in $2 \%$ FBS-containing medium.

\section{Plaque assays}

Dengue virus titers were measured using plaque assays on BHK-21 cells. Briefly, BHK-21 monolayers were grown to $90 \%$ confluence in 24 -well plates and incubated with serially diluted virus supernatants for $1 \mathrm{hr}$ at $37^{\circ} \mathrm{C}$. The wells were subsequently overlaid with Dulbecco's modified Eagle's medium, 1\% Aquacide and 5\% FBS and incubated for 5-8 days. Cells were fixed with $10 \%$ formaldehyde for 20 min and stained with crystal violet for 20 min to visualize plaques. Plaque forming units (PFU) were calculated.

\section{Double stranded RNA preparation}

404 Primers complementary to specific target gene sequences were designed using the E-RNAi

405 website and the T7 promoter sequence was incorporated into both forward and reverse primers.

406 The primers were used to amplify $\sim 500 \mathrm{bp}$ regions from target genes by PCR using cDNA

407 extracted from Aag2 cells as template. PCR products were purified using the Qiagen PCR

408 purification kit. In vitro transcription reactions (Promega MegaScript T7 transcription kit) 
containing $\sim 400 \mathrm{ng}$ of the purified PCR product, $2 \mathrm{ml}$ of 10X reaction buffer, $2 \mathrm{ml}$ of each rNTP and $2 \mathrm{ml}$ of $\mathrm{T} 7$ polymerase in a total volume of $20 \mathrm{ml}$ were incubated overnight at $37^{\circ} \mathrm{C}$. dsRNAs

411 were DNAse-treated at $37^{\circ} \mathrm{C}$ for 30 min and purified using the RNEasy Mini kit. After annealing 412 by heating at $95^{\circ} \mathrm{C}$ for $2 \mathrm{~min}$ and slow cooling for $2 \mathrm{hrs}$ at $37^{\circ} \mathrm{C}$ aliquots were stored at $-80^{\circ} \mathrm{C}$.

\section{Transfection}

416 For DENV2 virus generation, $1.5 \times 10^{5} \mathrm{BHK}-21$ cells were seeded in each well of a 24 -well plate 417 and transfected with $1 \mathrm{mg}$ of DENV2 RNA using Lipofectamine 3000. Medium was changed 2 418 hrs post transfection. For RaPID experiments, $10^{7} \mathrm{C} 6 / 36$ cells were seeded onto a $10 \mathrm{~cm}$ dish 419 and co-transfected with 12 mg of pBG34-BoxB-RNA expressing plasmid and 1.5 mg of pBG34-

420 BASU plasmid using $30 \mathrm{ml}$ of Lipofectamine 3000 . Transfection mix was prepared in $1 \mathrm{ml}$ 421 OptiMEM and added to complete medium. Medium was changed $24 \mathrm{hrs}$ post transfection. At 48 422 hrs post transfection, biotin was added to the medium at a final concentration of $10 \mathrm{mM}$ for $3 \mathrm{hrs}$.

423 Cells were then harvested for RaPID experiments. For RNAi experiments, $2 \times 10^{5}$ Aag2 cells 424 were seeded in each well of a 24-well plate and transfected with $500 \mathrm{ng}$ of dsRNA or $50 \mathrm{nM}$ 425 siRNA using $2 \mathrm{ml}$ of Dharmafect-2 transfection reagent (Dharmacon). $100 \mathrm{ml}$ of OptiMEM was 426 used to prepare the transfection mix and added to $1 \mathrm{ml}$ of complete medium in each well.

427 Medium was changed at 6 hrs post transfection.

429 RNA-protein interaction detection (RaPID)

$43110^{7} \mathrm{C} 6 / 36$ cells were co-transfected with BoxB tagged-RNA and BASU expressing plasmids. 48 432 hrs post transfection, the medium was supplemented with biotin for $3 \mathrm{hrs}$. Cells were gently 433 washed with cold 1 X PBS on the plate, harvested and lysed with $600 \mu$ lysis buffer $(0.5 \mathrm{M} \mathrm{NaCl}$, $43450 \mathrm{mM}$ Tris- $\mathrm{HCl}, 0.2 \%$ SDS, $1 \mathrm{mM}$ DTT) at room temperature. Next, $52 \mu \mathrm{l}$ of $25 \%$ Triton X-100 
435 was added to lysates and sonicated three times at an amplitude of $10 \%$ for $10 \mathrm{~s}$ at $30 \mathrm{~s}$

436 intervals. Further, $652 \mathrm{~mL}$ of cold $50 \mathrm{mM}$ Tris $(\mathrm{pH} 7.5)$ was added to lysates and briefly

437 sonicated. Lysates were cleared by centrifugation at $14000 \mathrm{rpm}$ for $10 \mathrm{~min}$ at $4^{\circ} \mathrm{C}$. Clarified

438 lysates were diluted in equal volume with 50mM Tris $(\mathrm{pH} \mathrm{7.5)}$ and centrifuged in $3 \mathrm{k}$ MWCO

$43915 \mathrm{ml}$ conical filters at $3900 \mathrm{rpm}$ for $1 \mathrm{hr}$ to remove free biotin. Supernatants from each filter were

440 transferred into eppendorfs and protein concentrations were determined using Pierce Protein

441 Quantitation Assay (ThermoFisher). Protein concentrations across samples were normalized to

$4424 \mathrm{mg} / \mathrm{ml}$ using 50mM Tris ( $\mathrm{pH}$ 7.5). Biotinylated proteins were pulled down using MagResyn

443 streptavidin beads with overnight rotation at $4^{\circ} \mathrm{C}(35 \mathrm{ml}$ beads per $\mathrm{mg}$ protein). Beads were

444 washed with a series of buffers for 5 min each at RT (Wash buffer 1: 2\% SDS. Wash buffer 2:

$445 \quad 0.1 \%$ Na-DOC, $1 \%$ Triton X-100, 0.5M NaCl, 50mM HEPES pH 7.5, $1 \mathrm{mM}$ EDTA. Wash buffer 3 :

$446 \quad 0.5 \% \mathrm{Na}-\mathrm{DOC}, 250 \mu \mathrm{M} \mathrm{LiCl}, 0.5 \% \mathrm{NP}-40,10 \mathrm{mM}$ Tris-HCl, $1 \mathrm{mM}$ EDTA) and finally with $50 \mathrm{mM}$

447 Tris $(\mathrm{pH}$ 7.5). Washed beads were submitted to the Stanford Mass Spectrometry facility for

448 downstream processing and LC-MS/MS analysis. Spectral counts of the identified peptides

449 were filtered using CRAPome to eliminate background contaminants and probability scores

450 were generated to identify peptides enriched in the experimental samples versus controls.

452 qPCR

454 Total RNA was isolated from cells harvested in TRIzol (Invitrogen) according to manufacturer's

455 protocol. $1 \mathrm{mg}$ of RNA was used for cDNA synthesis using High Capacity RNA-to-cDNA kit

456 (Thermo Fisher, 4387406). $2 \mathrm{ml}$ of cDNA was used to amplify target genes using the Power Up

457 SyBR Green master mix (Thermo Fisher, A25742). Ct values of target genes were normalized

458 to Ct values of the housekeeping gene, RPL32 to calculate fold-changes in RNA abundances. 
462 Cells were washed once with PBS and harvested in $100 \mathrm{ml}$ of Renilla Luciferase Activity buffer

463 (Promega). $10 \mu \mathrm{l}$ aliquots were used to measure luminescence using the Luciferase Assay

464 System (Promega) and the Glomax 20/20 luminometer with a 10 s integration time.

466 Northern blot analysis

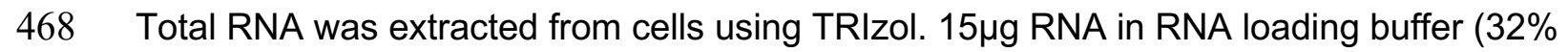

469 formamide, 1x MOPS-EDTA-Sodium acetate (MESA, Sigma) and 4.4\% formaldehyde) was

470 denatured at $65^{\circ} \mathrm{C}$ for $10 \mathrm{~min}$ and resolved on a $1 \%$ agarose gel containing $1 \mathrm{x}$ MESA and $3.7 \%$

471 formaldehyde. The RNA was transfered and UV crosslinked to a Zeta-probe membrane (Bio-

472 Rad). Transfer efficiency was assessed by visualizing ribosomal RNA on the membrane using

473 methylene blue stain. The membrane was destained and hybridized with $\alpha-{ }^{32} \mathrm{P}$ dATP labelled

474 DNA probes (RadPrime, Invitrogen) complementary to the DENV $3^{\prime} U T R$ at $65^{\circ} \mathrm{C}$ for $3 \mathrm{hrs}$ using

475 ExpressHyb hybridization buffer (Clontech). Autoradiographs were quantified using ImageQuant 476 (GE Healthcare).

\section{Western Blot}

480 Cells were washed with PBS and lysed in RIPA buffer (50mM Tris (pH8.0), $150 \mathrm{mM} \mathrm{NaCl,} 0.5 \%$

481 sodium deoxycholate, $0.1 \%$ SDS, and $1 \%$ Triton X-100) containing Complete EDTA-free

482 protease inhibitors (Roche) for $30 \mathrm{~min}$ on ice. Cell lysates were clarified by centrifugation at

$48314000 \mathrm{rpm}$ for $5 \mathrm{~min}$ at $4^{\circ} \mathrm{C} .50 \mu \mathrm{g}$ of cell lysate was mixed with $5 x$ SDS loading dye (Thermo

484 Fisher), denatured at $90^{\circ} \mathrm{C}$ for $10 \mathrm{~min}$ and resolved on a $10 \%$ SDS-polyacrylamide gel. Proteins

485 were transferred onto a PVDF membrane (Millipore), blocked with 5\% non-fat milk in PBS-T and

486 membranes were incubated with primary antibodies. Horse-radish peroxidase-conjugated 
487 secondary antibodies were used to visualize proteins using Pierce ECL Western Blot Substrate

488 (Thermo Fisher) following manufacturer's protocol. The following primary antibodies were used

489 for western blot analysis: Anti-NS3 antibody (GTX124252, GeneTex), Anti-NS4B antibody

490 (GTX124250, GeneTex), Anti-NS5 antibody (GTX103350, GeneTex), Anti-Capsid antibody

491 (GTX103343, GeneTex), Anti-Actin antibody (A2066, Sigma), Anti-Loqs antibody (custom

492 generated by GenScript), Anti-HA antibody (ab130275, Abcam) and Anti-GAPDH antibody

493 (GTX627408, GeneTex).

495 Polysome profile

$49610^{7}$ Aag2 cells were seeded onto $10 \mathrm{~cm}$ plates and transfected with dsRNAs targeting GFP, 497 Sec61A1 or Loqs genes. 24 hrs post transfection, cells were infected with DENV2-NGC at a $498 \mathrm{MOI}$ of $1.48 \mathrm{~h}$ post infection, cells were treated for $3 \mathrm{~min}$ with cycloheximide $(100 \mu \mathrm{g} / \mathrm{mL})$ at $49937^{\circ} \mathrm{C}$, washed twice in cold PBS containing $100 \mu \mathrm{g} / \mathrm{mL}$ cycloheximide, and lysed for $10 \mathrm{~min}$ on 500 ice in gradient buffer $(150 \mathrm{mM} \mathrm{KCl}, 15 \mathrm{mM}$ Tris-HCl, $\mathrm{pH}$ 7.5, $15 \mathrm{mM} \mathrm{MgCl}$, $100 \mu \mathrm{gg} / \mathrm{mL}$ 501 cycloheximide, $1 \mathrm{mg} / \mathrm{mL}$ heparin) containing $1 \%$ Triton $\mathrm{X}-100$. Lysates were cleared by 502 centrifugation at $14000 \mathrm{rpm}$ for $10 \mathrm{~min}$ at $4^{\circ} \mathrm{C}$ and layered onto $10 \%$ to $60 \%$ sucrose gradients 503 composed of the above gradient buffer. Gradients were spun in an SW41 ultra- centrifuge rotor 504 for 2 h $45 \mathrm{~min}$ at $35,000 \mathrm{rpm}$ at $4^{\circ} \mathrm{C}$. Fractions were collected using the Isco Retriever II/UA-6 505 detector system. RNA was isolated from each fraction using the RNEasy mini-kit and used for 506 cDNA preparation and qPCR analysis.

\section{RNP immunoprecipitation}

$50910^{7}$ Aag2 cells were seeded onto $10 \mathrm{~cm}$ plates and transfected with plasmids expressing HA510 GFP or HA-Loqs PA/PB. 24 hrs post transfection, cells were infected with DENV2-NGC at a $511 \mathrm{MOI}$ of 1. $48 \mathrm{hrs}$ post infection, cells were washed with cold 1X PBS on the plate and harvested 
512 in $1 \mathrm{ml}$ of Pierce IP lysis buffer containing protease inhibitors. Lysates were incubated on ice for

$51330 \mathrm{~min}$, clarified by centrifugation at $14000 \mathrm{rpm}$ for $10 \mathrm{~min}$ at $4^{\circ} \mathrm{C}$ and protein concentrations in

514 the samples were estimated by Bradford assay. For each sample, a total of $400 \mathrm{mg}$ protein at a

515 concentration of $<1 \mathrm{mg} / \mathrm{ml}$ was precleared by rotating with $10 \mathrm{~m}$ I of Protein G Dynabeads for 1

$516 \mathrm{hr}$ at $4^{\circ} \mathrm{C}$. Lysates were subsequently incubated with Anti-HA Dynabeads overnight at $4^{\circ} \mathrm{C}$ with

517 rotation. RNase treatment was performed by incubating lysates with RnaseA/T1 $(0.4 \mathrm{U} / \mathrm{ml}$

518 RNase A and $16.6 \mathrm{U} / \mathrm{ml}$ RNase T1) for $15 \mathrm{~min}$ at $37^{\circ} \mathrm{C}$ prior to addition of anti-HA beads. For

519 immunoprecipitating endogenous Loqs, lysates were incubated with beads saturated overnight

520 with $4 \mathrm{mg}$ of anti-Loqs antibody or a rabbit IgG isotype control. The following day, beads were

521 washed thrice with cold Pierce IP lysis buffer and twice with the same buffer supplemented with

$522500 \mathrm{mM} \mathrm{NaCl}$. For RNA elution, beads were treated with $30 \mathrm{mg}$ of ProteinaseK in IP lysis buffer

523 containing $0.1 \%$ SDS. RNA was extracted using TRIzol-LS and analyzed by northern blot or RT-

524 qPCR. For protein co-immunoprecipitation experiments, proteins were eluted from beads by

525 boiling with $1 X$ SDS gel loading buffer and analyzed by Western blot.

\section{Detergent fractionation of cells}

$5292 \times 10^{6}$ Aag2 cells were seeded onto each well of a 6 well plate and infected with DENV at a MOI

530 of 1 for $48 \mathrm{hrs}$. Cells were gently washed on the plate with $3 \mathrm{ml}$ of cold PBS, harvested in $1 \mathrm{ml}$

531 PBS and pelleted by centrifugation at $1000 \mathrm{~g}$ for 5 min at $4^{\circ} \mathrm{C}$. Next, cells were lysed by

532 resuspending in $1 \mathrm{ml}$ permeabilization buffer (110mM KOAc, 25mM HEPES-KOH (pH-7.5),

$5332.5 \mathrm{mM} \mathrm{Mg}(\mathrm{OAc}) 2,1 \mathrm{mM}$ EGTA, 0.015\% digitonin, $1 \mathrm{mM}$ DTT, 40U/ml RNAseOUT), incubated

534 for $5 \mathrm{~min}$ at $4^{\circ} \mathrm{C}$ and pelleted as above. Supernatants (cytosolic fraction) were transferred into

535 fresh Eppendorf tubes and remaining pellets were washed by resuspension in $5 \mathrm{ml}$ of wash

536 buffer (110mM KOAc, 25mM HEPES-KOH (pH 7.5), 2.5mM Mg(OAc)2, 1mM EGTA, 0.004\%

537 digitonin, $1 \mathrm{mM}$ DTT) and pelleted as above. Washed pellets were resuspended in $250 \mathrm{ml}$ lysis 
538 buffer (400mM KOAc, 25mM HEPES-KOH pH 7.5, 15mM Mg(OAc)2, 1\% (v/v) NP-40, 0.5\%

$539(\mathrm{w} / \mathrm{v})$ sodium deoxycholate, $1 \mathrm{mM}$ DTT) to solubilize the membrane fractions, incubated for $5 \mathrm{~min}$

540 at $4^{\circ} \mathrm{C}$ and centrifuged at $7500 \mathrm{~g}$ for $10 \mathrm{~min}$ at $4^{\circ} \mathrm{C}$. Supernatants (membrane fraction) were

541 transferred into fresh tubes while the remaining pellets were saved (nuclear fraction). $20 \mathrm{ml}$ from

542 each fraction was analyzed by western blot.

\section{RNA fluorescence in situ hybridization (RNA-FISH)}

545 RNA-FISH was performed using the RNA View Cell Plus assay kit (Cat. No.88-19000-99,

546 ThermoFisher) according to the manufacturer's protocol. Briefly, $2 \times 10^{5}$ Aag2 cells were plated

547 onto coverslips in 24 well plates, infected with DENV at a MOI of 1 and fixed using $4 \%$

548 paraformaldehyde for $30 \mathrm{~min}$ at RT. Cells were permeabilized, blocked and incubated with Anti-

549 Loqs or anti-NS3 primary antibodies at a dilution of 1:200 followed by incubation with Alexa-

550 Fluor 488 secondary antibodies (Invitrogen) at a dilution of 1:500. After antibody staining, cells

551 were washed with PBS and incubated with DNA probes complementary to the NS5 region of

552 DENV genomic RNA at $40^{\circ} \mathrm{C}$ for $2 \mathrm{hrs}$ (1:100 dilution). Cells were then sequentially treated at

$55340^{\circ} \mathrm{C}$ for $1 \mathrm{hr}$ with the pre-amplifier mix, amplifier mix and Label Probe mix and finally mounted

554 on slides using Fluoromount-G with DAPI. Imaging analysis was carried out at the Stanford

555 Imaging Facility.

556 Infrared UV-crosslinking immunoprecipitation (irCLIP) of Loqs

$55710^{7}$ Aag2 cells were seeded onto $10 \mathrm{~cm}$ plates, transfected the next day with HA-GFP or HA-

558 Loqs PA/PB plasmids and infected the following day with DENV2-NGC at MOI of 1. After 48 hrs,

559 infected cells were UV crosslinked at $0.35 \mathrm{~J} / \mathrm{cm} 2$, lysed in CLIP lysis buffer (50 mM HEPES, 200

$560 \mathrm{mM} \mathrm{NaCl}, 1 \mathrm{mM}$ EDTA, $10 \%$ glycerol, 0.1\% NP-40, 0.2\% Triton X-100, 0.5\% N-

561 lauroylsarcosine). Isolation and processing of RNA-protein complexes were performed as

562 described [13]. Briefly, sequential immunoprecipitations were performed using the anti-HA 
563 antibody followed by the anti-Loqs antibody for 8 hours at $4^{\circ} \mathrm{C}$ on rotation. RNP-complexes were

564 resolved on SDS-PAGE gels, transferred onto nitrocellulose, excised and the RNA isolated for

565 library preparation. The Dengue genome was downloaded from NCBI (GenBank: AF038403.1)

566 and the mosquito genome (AaegL5) was downloaded from Ensembl. Genomes were indexed

567 using hisat2-build. Trimmed reads were mapped to the dengue genome and then the mosquito

568 genome using hisat2. Bam files from the three replicates were merged and then visualized

569 using the Integrative Genomics Viewer. For the dengue genome mapping results, reads

570 mapping to the forward and reverse strand were separated using "samtools view $-\mathrm{F} 20$ " and

571 "samtools view -f 16" and then viewed in IGV.

572

573 Acknowledgements

574 We are grateful to Karla Kirkegaard for many comments and critical reading of the manuscript.

575 We thank C. Adams, R. Leib and the Vincent Coates Foundation Mass Spectrometry

576 Laboratory, Stanford University Mass Spectrometry for help with mass spectrometry.

578 References

580 1. Bos S, Gadea G, Despres P. Dengue: a growing threat requiring vaccine development for 581 disease prevention. Pathog Glob Health. 2018;112(6):294-305. Epub 2018/09/15. doi: 582 10.1080/20477724.2018.1514136. PubMed PMID: 30213255; PubMed Central PMCID: 583 PMCPMC6381545.

585 2. Shivaprasad S, Sarnow P. The tale of two flaviviruses: subversion of host pathways by 586 RNA shapes in dengue and hepatitis C viral RNA genomes. Curr Opin Microbiol. 2021;59:79-85. 
587 Epub 2020/10/19. doi: 10.1016/j.mib.2020.08.007. PubMed PMID: 33070015; PubMed Central 588 PMCID: PMCPMC7854966.

590 3. Siriphanitchakorn T, Kini RM, Ooi EE, Choy MM. Revisiting dengue virus-mosquito 591 interactions: molecular insights into viral fitness. J Gen Virol. 2021;102(11). doi: 592 10.1099/jgv.0.001693. PubMed PMID: 34845981.

594 4. Clarke BD, Roby JA, Slonchak A, Khromykh AA. Functional non-coding RNAs derived 595 from the flavivirus 3' untranslated region. Virus Res. 2015;206:53-61. Epub 2015/02/11. doi: 596 10.1016/j.virusres.2015.01.026. PubMed PMID: 25660582.

$598 \quad$ 5. Yeh SC, Pompon J. Flaviviruses Produce a Subgenomic Flaviviral RNA That Enhances 599 Mosquito Transmission. DNA Cell Biol. 2018;37(3):154-9. Epub 2017/12/19. doi: 600 10.1089/dna.2017.4059. PubMed PMID: 29251994.

602 6. Villordo SM, Carballeda JM, Filomatori CV, Gamarnik AV. RNA Structure Duplications and 603 Flavivirus Host Adaptation. Trends Microbiol. 2016;24(4):270-83. Epub 2016/02/07. doi: 604 10.1016/j.tim.2016.01.002. PubMed PMID: 26850219; PubMed Central PMCID: 605 PMCPMC4808370.

607 7. Choksupmanee O, Tangkijthavorn W, Hodge K, Trisakulwattana K, 608 Phornsiricharoenphant W, Narkthong V, et al. Specific Interaction of DDX6 with an RNA Hairpin 609 in the 3' UTR of the Dengue Virus Genome Mediates G1 Phase Arrest. J Virol. 610 2021;95(17):e0051021. Epub 2021/06/17. doi: 10.1128/JVI.00510-21. PubMed PMID: 34132569; 611 PubMed Central PMCID: PMCPMC8354244. 
612 8. Ward AM, Bidet K, Yinglin A, Ler SG, Hogue K, Blackstock W, et al. Quantitative mass

613 spectrometry of DENV-2 RNA-interacting proteins reveals that the DEAD-box RNA helicase

614 DDX6 binds the DB1 and DB2 3' UTR structures. RNA Biol. 2011;8(6):1173-86. Epub 2011/10/01.

615 doi: 10.4161/rna.8.6.17836. PubMed PMID: 21957497; PubMed Central PMCID:

616 PMCPMC3256426.

618 9. Liao KC, Chuo V, Ng WC, Neo SP, Pompon J, Gunaratne J, et al. Identification and 619 characterization of host proteins bound to dengue virus 3' UTR reveal an antiviral role for quaking 620 proteins. RNA. 2018;24(6):803-14. Epub 2018/03/25. doi: 10.1261/rna.064006.117. PubMed 621 PMID: 29572260; PubMed Central PMCID: PMCPMC5959249.

623 10. Bidet K, Dadlani D, Garcia-Blanco MA. G3BP1, G3BP2 and CAPRIN1 are required for 624 translation of interferon stimulated mRNAs and are targeted by a dengue virus non-coding RNA. 625 PLoS Pathog. 2014;10(7):e1004242. Epub 2014/07/06. doi: 10.1371/journal.ppat.1004242. 626 PubMed PMID: 24992036; PubMed Central PMCID: PMCPMC4081823.

628 11. Manokaran G, Finol E, Wang C, Gunaratne J, Bahl J, Ong EZ, et al. Dengue subgenomic 629 RNA binds TRIM25 to inhibit interferon expression for epidemiological fitness. Science. 630 2015;350(6257):217-21. Epub 2015/07/04. doi: 10.1126/science.aab3369. PubMed PMID: 631 26138103; PubMed Central PMCID: PMCPMC4824004.

633 12. Ooi YS, Majzoub K, Flynn RA, Mata MA, Diep J, Li JK, et al. An RNA-centric dissection of 634 host complexes controlling flavivirus infection. Nat Microbiol. 2019;4(12):2369-82. Epub 635 2019/08/07. doi: 10.1038/s41564-019-0518-2. PubMed PMID: 31384002; PubMed Central 636 PMCID: PMCPMC6879806. 
637 13. Zarnegar BJ, Flynn RA, Shen Y, Do BT, Chang HY, Khavari PA. irCLIP platform for 638 efficient characterization of protein-RNA interactions. Nat Methods. 2016;13(6):489-92. Epub 639 2016/04/26. doi: 10.1038/nmeth.3840. PubMed PMID: 27111506; PubMed Central PMCID: 640 PMCPMC5477425.

642 14. Ren L, Ding S, Song Y, Li B, Ramanathan M, Co J, et al. Profiling of rotavirus 3'UTR643 binding proteins reveals the ATP synthase subunit ATP5B as a host factor that supports late644 stage virus replication. J Biol Chem. 2019;294(15):5993-6006. Epub 2019/02/17. doi: 645 10.1074/jbc.RA118.006004. PubMed PMID: 30770472; PubMed Central PMCID: 646 PMCPMC6463704.

648 15. Ramanathan M, Majzoub K, Rao DS, Neela PH, Zarnegar BJ, Mondal S, et al. RNA649 protein interaction detection in living cells. Nat Methods. 2018;15(3):207-12. Epub 2018/02/06. 650 doi: 10.1038/nmeth.4601. PubMed PMID: 29400715; PubMed Central PMCID: 651 PMCPMC5886736.

653 16. Filomatori CV, Carballeda JM, Villordo SM, Aguirre S, Pallares HM, Maestre AM, et al. 654 Dengue virus genomic variation associated with mosquito adaptation defines the pattern of viral 655 non-coding RNAs and fitness in human cells. PLoS Pathog. 2017;13(3):e1006265. Epub 656 2017/03/07. doi: 10.1371/journal.ppat.1006265. PubMed PMID: 28264033; PubMed Central 657 PMCID: PMCPMC5354447.

660 17. Kelkar A, Dobberstein B. Sec61beta, a subunit of the Sec61 protein translocation channel 661 at the endoplasmic reticulum, is involved in the transport of Gurken to the plasma membrane. 
662 BMC Cell Biol. 2009;10:11. Epub 2009/02/20. doi: 10.1186/1471-2121-10-11. PubMed PMID:

663 19226464; PubMed Central PMCID: PMCPMC2653466.

18. Haac ME, Anderson MA, Eggleston H, Myles KM, Adelman ZN. The hub protein

666 loquacious connects the microRNA and short interfering RNA pathways in mosquitoes. Nucleic

667 Acids Res. 2015;43(7):3688-700. Epub 2015/03/15. doi: 10.1093/nar/gkv152. PubMed PMID:

668 25765650; PubMed Central PMCID: PMCPMC4402513.

19. Shah PS, Link N, Jang GM, Sharp PP, Zhu T, Swaney DL, et al. Comparative FlavivirusHost Protein Interaction Mapping Reveals Mechanisms of Dengue and Zika Virus Pathogenesis. Cell. 2018;175(7):1931-45 e18. Epub 2018/12/15. doi: 10.1016/j.cell.2018.11.028. PubMed

20. Nonhoff U, Ralser M, Welzel F, Piccini I, Balzereit D, Yaspo ML, et al. Ataxin-2 interacts with the DEAD/H-box RNA helicase DDX6 and interferes with P-bodies and stress granules. Mol Biol Cell. 2007;18(4):1385-96. Epub 2007/03/30. doi: 10.1091/mbc.e06-12-1120. PubMed PMID: 17392519; PubMed Central PMCID: PMCPMC1838996.

21. McCann C, Holohan EE, Das S, Dervan A, Larkin A, Lee JA, et al. The Ataxin-2 protein is 681 required for microRNA function and synapse-specific long-term olfactory habituation. Proc Natl 682 Acad Sci U S A. 2011;108(36):E655-62. Epub 2011/07/29. doi: 10.1073/pnas.1107198108. 683 PubMed PMID: 21795609; PubMed Central PMCID: PMCPMC3169144.

685 22. Brackney DE, Scott JC, Sagawa F, Woodward JE, Miller NA, Schilkey FD, et al. C6/36 686 Aedes albopictus cells have a dysfunctional antiviral RNA interference response. PLoS Negl Trop 
687 Dis. 2010;4(10):e856. Epub 2010/11/05. doi: 10.1371/journal.pntd.0000856. PubMed PMID:

688 21049065; PubMed Central PMCID: PMCPMC2964293.

690 23. Sanchez-Vargas I, Scott JC, Poole-Smith BK, Franz AW, Barbosa-Solomieu V, Wilusz J, 691 et al. Dengue virus type 2 infections of Aedes aegypti are modulated by the mosquito's RNA 692 interference pathway. PLoS Pathog. 2009;5(2):e1000299. Epub 2009/02/14. doi: 693 10.1371/journal.ppat.1000299. PubMed PMID: 19214215; PubMed Central PMCID: 694 PMCPMC2633610.

24. Chin-Inmanu K, Suttitheptumrong A, Sangsrakru D, Mairiang D, Tangphatsornruang S, 697 Malasit P, et al. Complete Genome Sequences of Four Serotypes of Dengue Virus Prototype 698 Continuously Maintained in the Laboratory. Microbiol Resour Announc. 2019;8(19). Epub 699 20190509. doi: 10.1128/MRA.00199-19. PubMed PMID: 31072897; PubMed Central PMCID: PMCPMC6509522.

25. Costes SV, Daelemans D, Cho EH, Dobbin Z, Pavlakis G, Lockett S. Automatic and 703 quantitative measurement of protein-protein colocalization in live cells. Biophys J. 704 2004;86(6):3993-4003. Epub 2004/06/11. doi: 10.1529/biophysj.103.038422. PubMed PMID: 705 15189895; PubMed Central PMCID: PMCPMC1304300.

707 26. Swarbrick CMD, Basavannacharya C, Chan KWK, Chan SA, Singh D, Wei N, et al. NS3 708 helicase from dengue virus specifically recognizes viral RNA sequence to ensure optimal 709 replication. Nucleic Acids Res. 2017;45(22):12904-20. Epub 2017/11/23. doi: 710 10.1093/nar/gkx1127. PubMed PMID: 29165589; PubMed Central PMCID: PMCPMC5728396. 
712 27. Boldescu V, Behnam MAM, Vasilakis N, Klein CD. Broad-spectrum agents for flaviviral

713 infections: dengue, Zika and beyond. Nat Rev Drug Discov. 2017;16(8):565-86. Epub 2017/05/06.

714 doi: 10.1038/nrd.2017.33. PubMed PMID: 28473729; PubMed Central PMCID:

715 PMCPMC5925760.

716

718 28. Sofia MJ, Chang W, Furman PA, Mosley RT, Ross BS. Nucleoside, nucleotide, and non-

719 nucleoside inhibitors of hepatitis C virus NS5B RNA-dependent RNA-polymerase. J Med Chem.

720 2012;55(6):2481-531. Epub 20120123. doi: 10.1021/jm201384j. PubMed PMID: 22185586.

722 29. Varjak M, Maringer K, Watson M, Sreenu VB, Fredericks AC, Pondeville E, et al. Aedes 723 aegypti Piwi4 Is a Noncanonical PIWI Protein Involved in Antiviral Responses. mSphere. 724 2017;2(3). Epub 2017/05/13. doi: 10.1128/mSphere.00144-17. PubMed PMID: 28497119; 725 PubMed Central PMCID: PMCPMC5415634.

727 30. Goertz GP, van Bree JWM, Hiralal A, Fernhout BM, Steffens C, Boeren S, et al. 728 Subgenomic flavivirus RNA binds the mosquito DEAD/H-box helicase ME31B and determines 729 Zika virus transmission by Aedes aegypti. Proc Natl Acad Sci U S A. 2019;116(38):19136-44. 730 Epub 2019/09/07. doi: 10.1073/pnas.1905617116. PubMed PMID: 31488709; PubMed Central 731 PMCID: PMCPMC6754610.

733 31. Garcia-Moreno M, Jarvelin AI, Castello A. Unconventional RNA-binding proteins step into 734 the virus-host battlefront. Wiley Interdiscip Rev RNA. 2018;9(6):e1498. Epub 2018/08/10. doi: 735 10.1002/wrna.1498. PubMed PMID: 30091184; PubMed Central PMCID: PMCPMC7169762. 
737 32. Jagannathan S, Hsu JC, Reid DW, Chen Q, Thompson WJ, Moseley AM, et al.

738 Multifunctional roles for the protein translocation machinery in RNA anchoring to the endoplasmic

739 reticulum. J Biol Chem. 2014;289(37):25907-24. Epub 2014/07/27. doi:

740 10.1074/jbc.M114.580688. PubMed PMID: 25063809; PubMed Central PMCID:

741 PMCPMC4162190.

742

743 33. Olmo RP, Ferreira AGA, Izidoro-Toledo TC, Aguiar E, de Faria IJS, de Souza KPR, et al.

744 Control of dengue virus in the midgut of Aedes aegypti by ectopic expression of the dsRNA-

745 binding protein Loqs2. Nat Microbiol. 2018;3(12):1385-93. Epub 2018/10/31. doi:

746 10.1038/s41564-018-0268-6. PubMed PMID: 30374169.

Author Contributions

Conceptualization: Peter Sarnow, Shwetha Shivaprasad

751 Funding acquisition: Peter Sarnow, Ryan Flynn

752 Formal analysis: Shwetha Shivaprasad, Kuo-Feng Weng, Ryan Flynn, Julia Belk, Peter

753 Sarnow

754 Investigation: Shwetha Shivaprasad, Kuo-Feng Weng, Ryan Flynn, Julia Belk, Peter Sarnow

755 Project administration: Peter Sarnow, Ryan Flynn

756 Supervision: Peter Sarnow, Ryan Flynn

757 Writing - original draft: Shwetha Shivaprasad

758 Writing -review \& editing: Shwetha Shivaprasad, Kuo-Feng Weng, Ryan Flynn, Julia Belk,

759 Peter Sarnow 
Fig 1. Diagram of the dengue viral (DENV) genome and strategy for the RNA-protein interaction (RAPID) assay. (A) DENV genome organization. The open reading frame encoding the three structural (C (capsid), prM/M (membrane), $\mathrm{E}$ (envelope)) proteins and seven non-structural (NS1, NS2A, NS2B, NS3, NS4A, NS4B, NS5) proteins flanked by 5' and 3' untranslated regions (UTR) are shown. The 3' UTR is organized into stem loops SLI, SLII, dumbbell structures DBI, DBII, a small hairpin (sHP) and a terminal 3' stem loop of RaPID assay. Plasmids expressing BoxB-flanked DENV2 of sfRNA3/4 and the $\lambda N$-biotin ligase fusion protein gene $(\lambda \mathrm{N}-\mathrm{HA}-\mathrm{Bir} \mathrm{A})$ were co-transfected into mosquito

774 cells. Subsequently, biotinylated proteins were captured using streptavidin beads and

775 identified by LC-MS/MS. (C) Schematic of the EDEN15 RNA motifs (3 repeats of 15bp each)

776 flanked by three BoxB RNA motifs each at their 5' and 3' ends. (D) DENV2 3'UTR (184-454nts)

777 flanked by two BoxB RNA motifs at its 5' end and three BoxB motifs at its 3' end. (E) Average

778 fold change of proteins enriched in EDEN15 RNA expressing cells relative to the scrambled

779 RNA control plotted against their SAINT probability scores. ELAV protein (shown in red) was

780 enriched by $\sim 40$ fold $\left(n=2,{ }^{* *} p<0.005\right)$. (F) Average fold change of proteins enriched

781 in DENV 3'UTR expressing cells relative to the scrambled RNA control is plotted against their

782 SAINT probability scores. Sec61A1 and Loquacious proteins (shown in red) were enriched by

$783 \sim 8$ fold and $\sim 5$ fold respectively $\left(n=4,{ }^{*} p<0.05,{ }^{* *} p<0.005\right)$.

Fig 2. Effects of Sec61A1 and Loquacious depletion on DENV2 RNA and protein abundances, and viral titers. (A) Experimental outline. Mosquito Aag2 cells were transfected with double stranded RNAs (dsRNA) directed against GFP, Sec61A1, Loqs (targeting both PA 
NGC at an MOI of 0.1 and harvested 96 hrs post infection for analyses. (B) RT-qPCR

measurement of DENV RNA abundances in dsRNA-treated cells plotted as fold change

over treatment with dsGFP. Data was normalized to internal control RPL32 mRNA levels ( $n=3$, $\left.{ }^{*} p<0.05,{ }^{* *} p<0.005\right) .(C)$ Effects of dsRNA treatment on DENV RNA

793 and DENV subgenomic RNA (DENV-sfRNA) abundances, measured by Northern blot

794 analysis. Methylene blue (MB) staining of rRNA was used as a loading control. Representative

795 image from three independent experiments is shown. (D) Effects of dsRNA treatment on DENV

796 NS3 and actin protein levels examined by western blot analysis. Representative image from

797 three independent experiments is shown. (E) Effects of dsRNA treatment on infectious viral

798 titers determined by plaque forming assays (PFU/ml, $\left.n=4,{ }^{*} p<0.05\right)$.

Fig 3. Effects of Loqs depletion distinct RNA virus infections. Aag2 cells were infected with dengue virus (DENV), West Nile virus (WNV), yellow fever virus (YFV), Zika virus (ZIKV) or chikungunya virus (CHIKV) at a $\mathrm{MOI}$ of 0.1 and harvested at 96 hrs post infection. Viral RNA abundances were measured by qPCR using specific primers. Data is represented as average fold-change over dsGFP from three independent experiments.

Fig 4: Colocalization and interaction of Loqs protein with DENV RNA. (A) Fluorescent in

807 situ hybridization imaging of Aag2 cells infected with DENV2 at an MOI of 1 after 48 hrs. NS3

808 and Loqs proteins (shown in green) were visualized using labeled antibodies, while DENV RNA

809 (shown in red) was visualized using labeled antisense RNA probes. Costes p value was

810 calculated to measure the extent of colocalization of DENV2 RNA with NS3/Loqs proteins.

811 (B) Immunoprecipitation of HA-tagged Loqs from Aag2 cells infected with DENV2 at a MOI of

812 1. Aag2 cells transfected with HA-GFP or HA-Loqs PA/PB plasmids were infected with DENV2

813 for $48 \mathrm{~h}$, and immunoprecipitations were performed with anti-HA antibodies. Abundances of HA-

814 GFP and HA-Loqs in input lysates and immunoprecipitated material measured by western 
815 blot analysis. (C) DENV2 and RPL32 RNA abundances in immunoprecipitated

816 RNA (IP) and input RNA (10\%) were measured by semi-quantitative RT-PCR. A representative

817 agarose gel image from three independent experiments is shown. (D) DENV2

818 and Loqs mRNA abundances in immunoprecipitated RNA (IP) and input RNA (10\%) measured

819 by RT-qPCR. Data was normalized to RPL32 mRNA levels $\left(n=3,{ }^{* * *} p=0.0006\right)$.

821 Fig 5. Effect of Loqs depletion on DENV RNA translation, replication and stability. (A)

822 Western blot analysis of NS3, Loqs and GAPDH protein abundances in cytosolic and ER

823 membrane fractions isolated from DENV2-infected Aag2 cell lysates at $72 \mathrm{hrs}$ post

824 infection. Representative image from three independent experiments is

825 shown. (B) Immunoprecipitation of HA-tagged Loqs from Aag2 cells infected with DENV2 at a

826 MOI of 1. Aag2 cells transfected with HA-GFP or HA-Loqs PA/PB plasmids were infected with

827 DENV2 for 72 hrs and immunoprecipitations were performed with anti-HA antibody with or

828 without RNaseA/T1 treatment. The abundances of DENV NS3, NS4B and capsid proteins in the

829 immunoprecipitated material (IP) and the input lysates (10\%) were determined by western

830 blot analysis. (C) Luciferase activities of wildtype and replication-defective DENV2 luciferase

831 replicons in C6/36 cells transfected with control siRNAs or siRNAs against Loqs (siLoqs-4 and

832 siLoqs -5 were used at a final concentration of $25 \mathrm{nM}$ each). C6/36 cells were transfected with

833 the indicated siRNAs followed by wildtype or replication-defective (NS5-GDD) replicon RNAs

834 and harvested at the indicated time points. Average luciferase expression from DENV replicons

835 from six independent replicates is shown. (D) Effect of Loqs depletion on DENV RNA stability.

836 Aag2 cells were transfected with the indicated siRNAs and infected with DENV2-NGC at MOI of

837 1. 24 hrs post infection, cells were treated with $20 \mu \mathrm{M} \mathrm{2}$ 'CMA to inhibit viral replication. Viral

838 RNA abundances at different times post 2'CMA treatment were measured by qPCR. Data is

839 represented as an average of two independent experiments. 
Fig S1. Effects of Loqs isoform depletion on DENV2-16681 (Thailand strain). (A) RT-qPCR

844 measurement of mRNA abundances in Aag2 cells transfected with the indicated dsRNAs.

845 Knockdown efficiency was measured using gene-specific primers $\left(n=3,{ }^{* *} p<0.005\right)$. (B) Western

846 blot analysis of Loqs protein abundance in dsGFP, dsLoqs, dsLoqs-PB and HA-Loqs PB

847 transfected Aag2 cells (C) Effects of dsRNA treatment on DENV2-16681(Thailand strain)

848 infection of Aag2 cells (MOI=0.1, 96 hrs), measured by RT-qPCR. Knockdown efficiency was

849 measured using gene-specific primers. Measurements are represented as fold-change over

850 dsGFP $\left(n=3,{ }^{*} p<0.05,{ }^{* *} p<0.005\right)$. (D) Effect of dsRNA treatment on extracellular abundances of

851 DENV2-16681 viral RNA in infected Aag2 cells, measured by RT-qPCR. Data is plotted as fold-

852 change over dsGFP from three independent experiments. (E) Cell culture supernatants from

853 dsRNA-treated cells were used to infect naive Aag2 cells and viral RNA abundances in these

854 cells were measured by RT-qPCR.

Fig S2. Effects of over-expression of different Loqs isoforms and different Loqs siRNAs

on DENV2 RNA abundances. (A) Aag2 cells were transfected with the indicated siRNAs for 24

858 hrs followed by DENV2 infection. Cells were harvested for qPCR at 96 hrs post infection.

859 Intracellular DENV2 RNA abundances are represented as average fold-change over siScr from

860 three independent experiments. (B) Aag2 cells were co-transfected with scrambled (siScr) or

861 Loqs (siLoqs 3'-2) siRNAs and the indicated plasmid DNAs. 24 hrs post transfection they were

862 infected with DENV2-NGC virus at a MOI of 0.1. Cells were harvested at 96 hrs post infection.

863 Intracellular DENV2 RNA abundances were measured by RT-qPCR and are represented

864 as average fold-change over the siScr from three independent experiments. 
Fig S3. Infrared UV-crosslinking immunoprecipitation (irCLIP) of Loqs. (A) Northern blot

867 analysis of RNA immunoprecipitated from DENV (MOI=1) infected Aag2 cell lysates

868 using Loqs antibody or a control antibody. DENV genomic RNA and DENV subgenomic

869 RNAs (DENV-sfRNA) were detected using radiolabeled RNA probes. Methylene blue (MB)

870 staining of rRNA is shown as a loading control. Representative image from three independent

871 immunoprecipitation experiments is shown. $(B, C)$ Aag2 cells were transfected with HA-GFP or

872 HA-Loqs PA/PB plasmids. 24 hrs post transfection, cells were infected with DENV2-NGC at a

$873 \mathrm{MOI}$ of 1 . Cells were UV irradiated at $254 \mathrm{~nm}$ to covalently crosslink RNA-protein interactions

874 and subjected to irCLIP with anti-Loqs followed by anti-HA antibodies. irCLIP RT

875 stops were mapped at base resolution to the DENV genome. The read density across positive-

876 (B) and negative- (C) sense DENV RNAs is represented as an average of three independent

877 experiments.

Fig S4. Polysome analysis of dsRNA-treated Aag2 cells infected with DENV2 at an MOI of

8801 for $48 \mathrm{~h}$. (A) DENV2 RNA abundance in each polysome fraction was measured by RT-

881 qPCR and plotted as a percentage of the total RNA. A representative graph from three

882 independent experiments is shown. (B) DENV2 RNA abundance in indicated polysome fractions 883 plotted as an average from three independent experiments.

Fig S5. Effect of Dicer depletion on Loqs inhibition of DENV replication. (A) AF319 Dicer-2

886 knock-out $(\mathrm{KO})$ cells were transfected with the indicated siRNAs. 24 hrs after siRNA

887 transfection, cells were infected with luciferase expressing DENV2 virus. Luciferase expression

888 in cell lysates was measured at the indicated time points and represented as an average from

889 three independent experiments. (B) AF319 Dicer-2 KO cells were transfected with the indicated

890 siRNAs. At 24 hrs after siRNA transfection, cells were transfected with luciferase expressing 
bioRxiv preprint doi: https://doi.org/10.1101/2021.12.03.471060; this version posted December 3, 2021. The copyright holder for this preprint

(which was not certified by peer review) is the author/funder, who has granted bioRxiv a license to display the preprint in perpetuity. It is made available under aCC-BY 4.0 International license.

891 DENV2-NGC replicon RNAs. Luciferase expression in cell lysates was measured 96 hrs post

892 transfection.

893

894

895

896

897 
$\mathbf{A}$

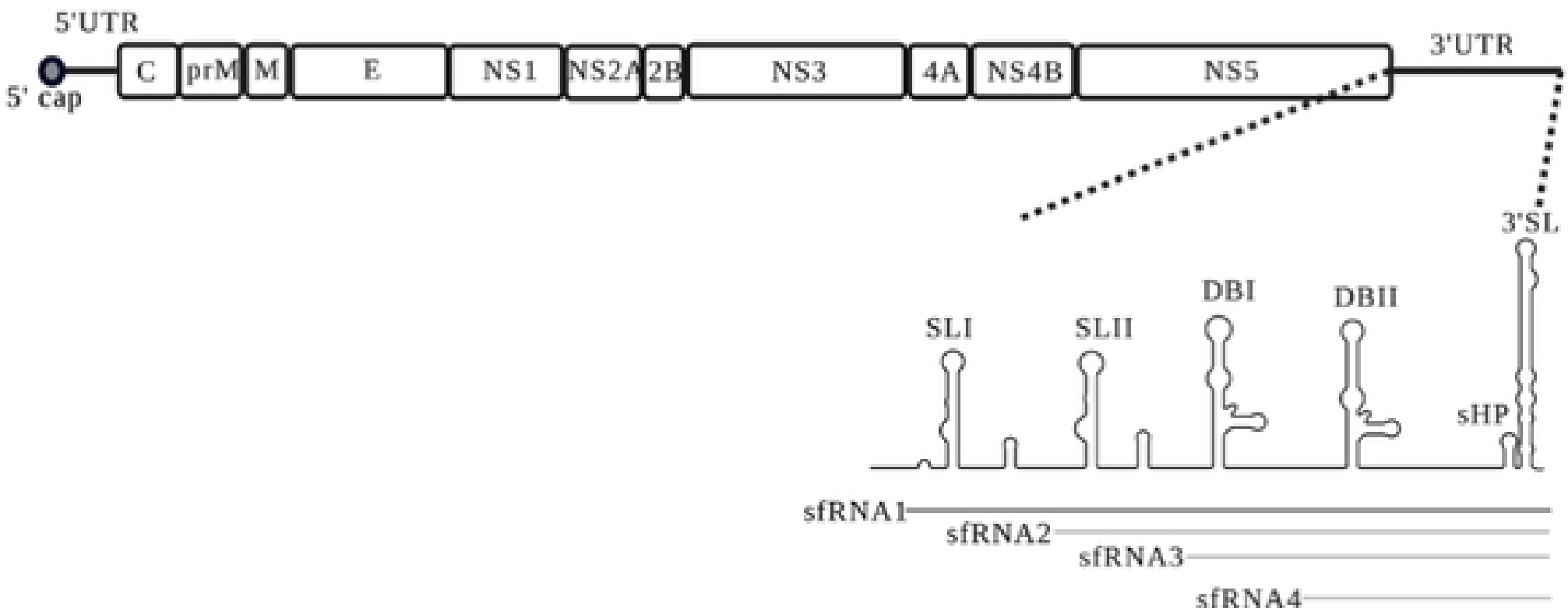

B

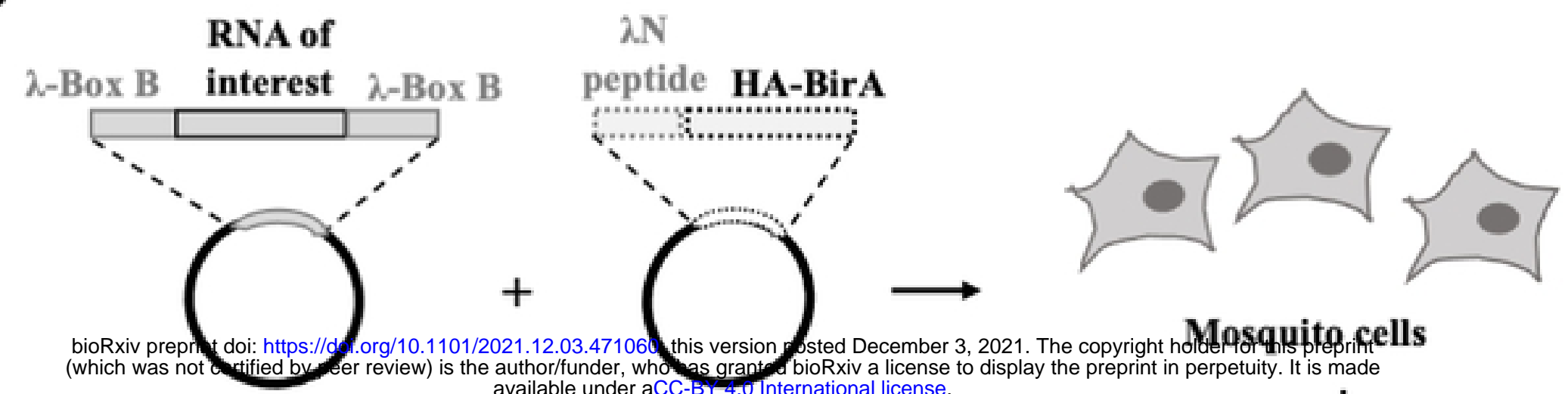

BoxB-tagged RNA $\lambda$ N-biotin ligase

fusion protein

Biotinylation

Streptavidin capture

LC-MS/MS

C

D

3'SL
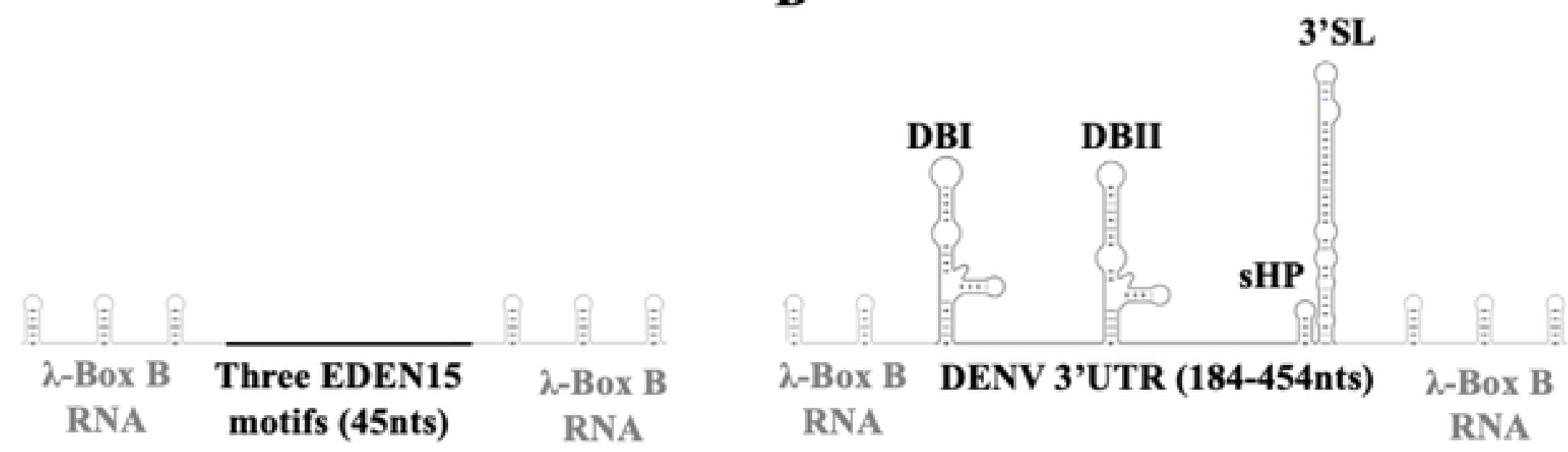

$\mathbf{E}$

$\mathbf{F}$

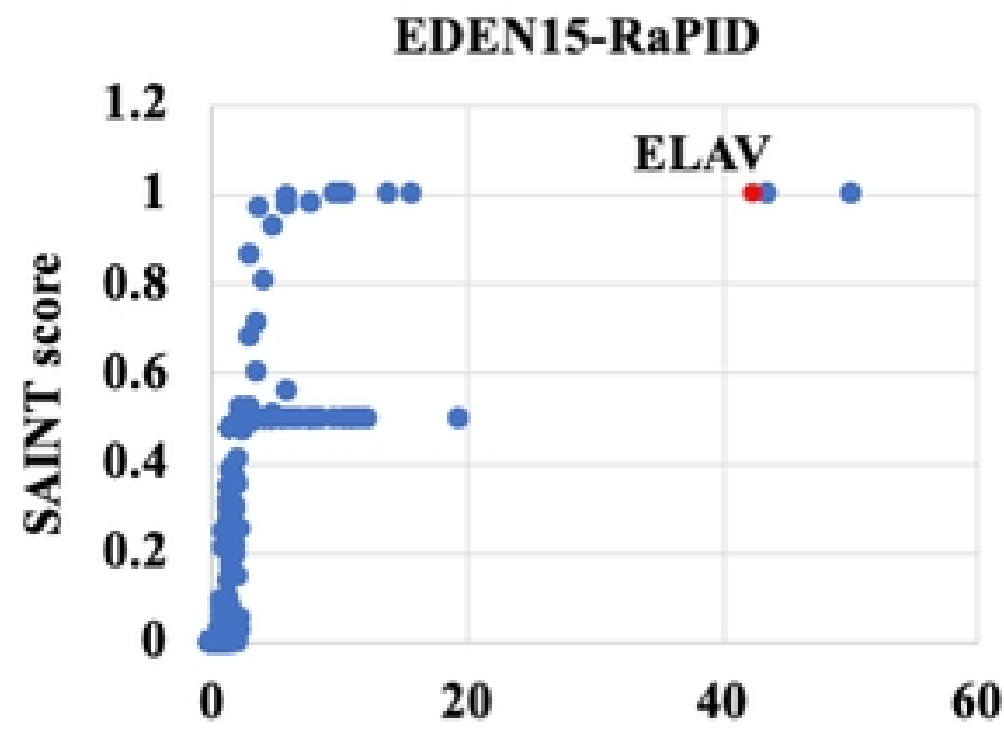

Average Fold enrichment

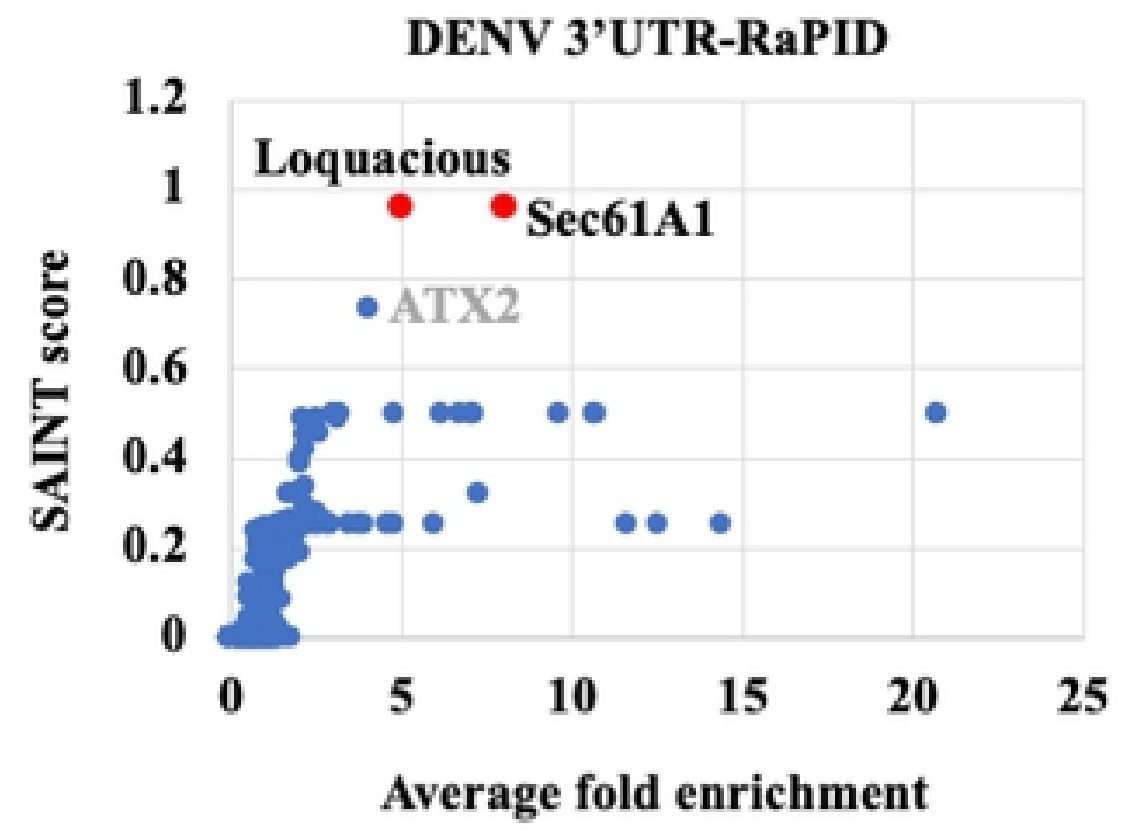

Fig. 1 


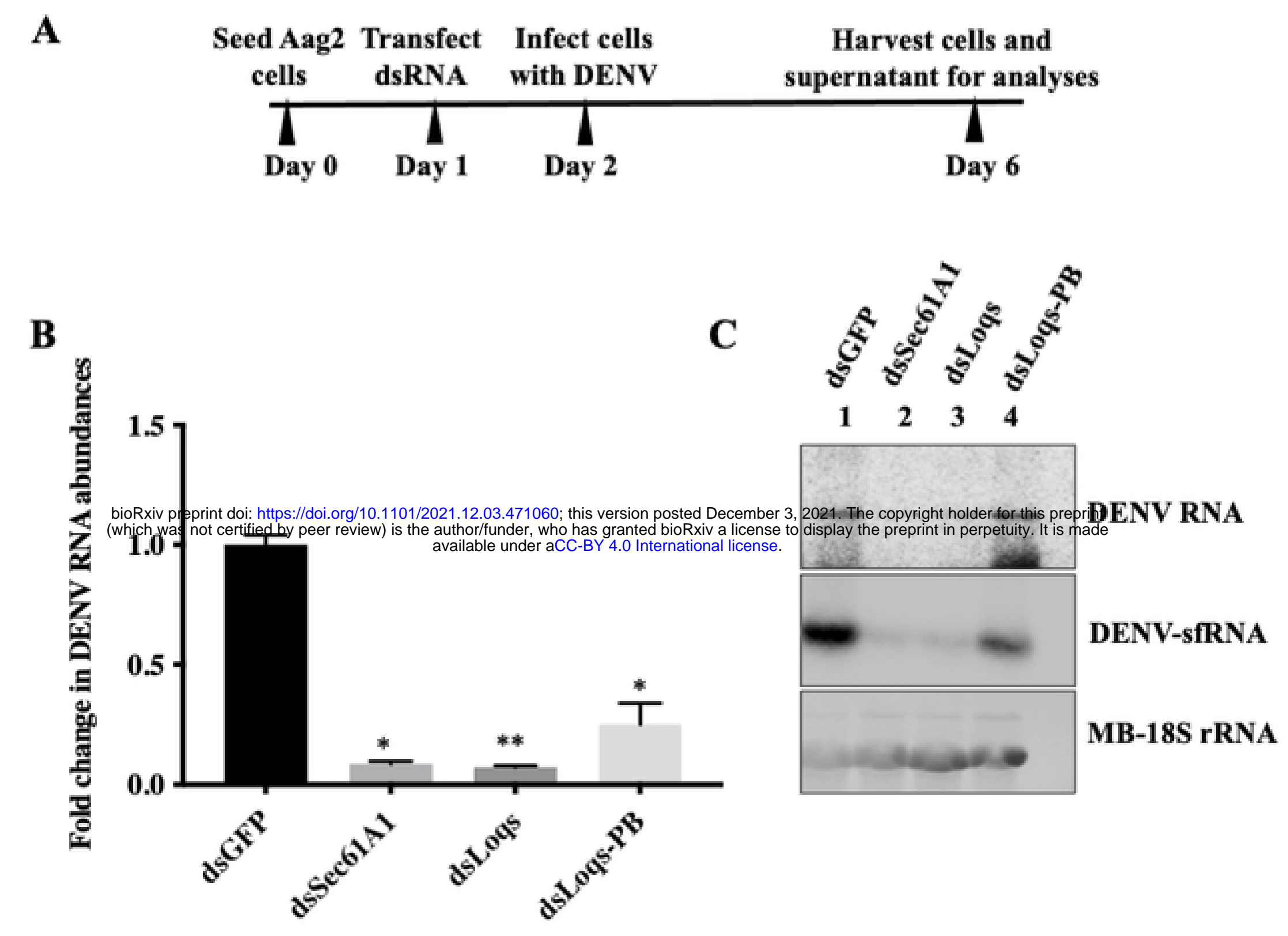

D

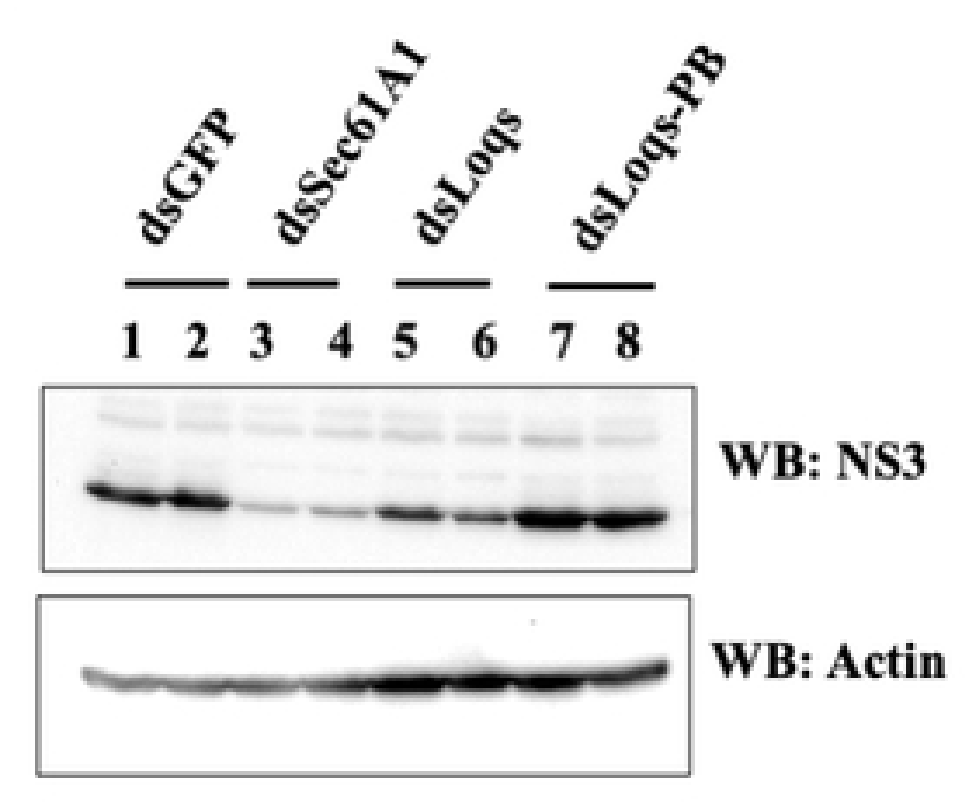

E

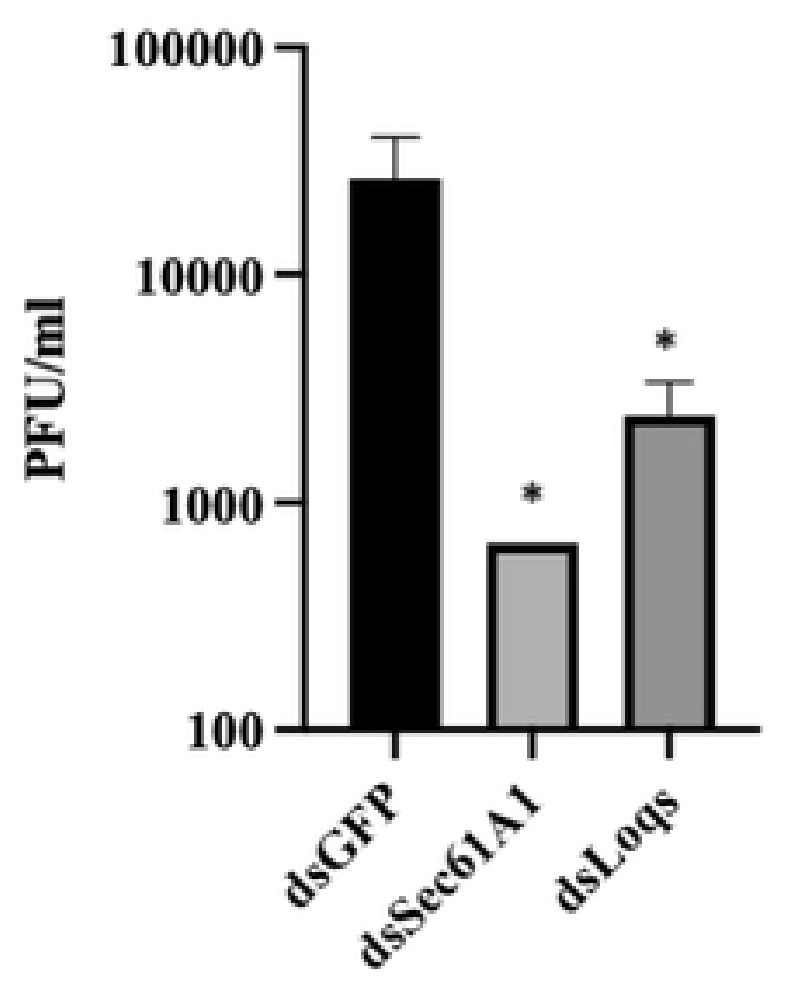

Fig. 2 


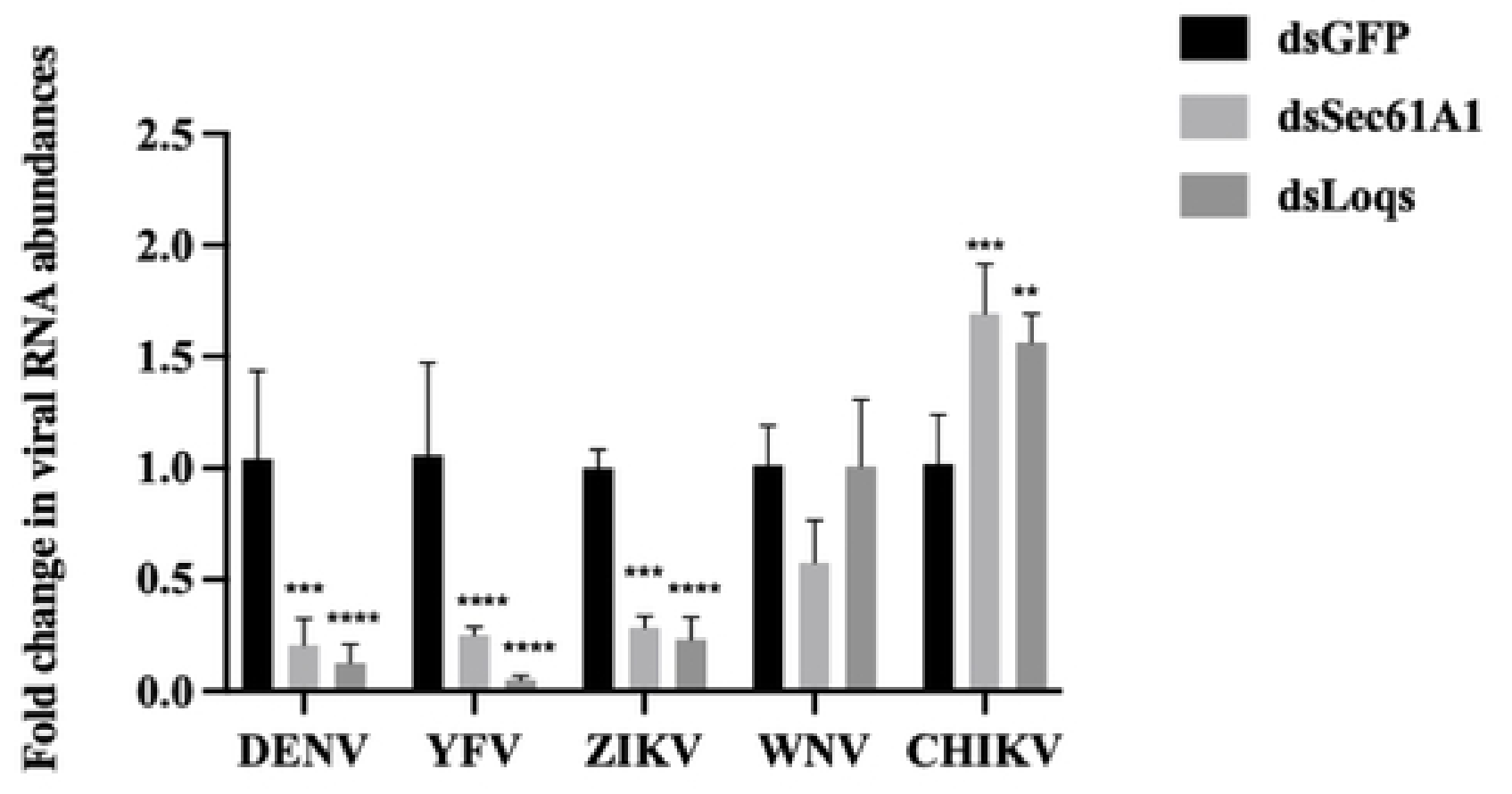

bioRxiv preprint doi: https://doi.org/10.1101/2021.12.03.471060; this version posted December 3, 2021. The copyright holder for this preprint 列

Fig. 3 
$\mathbf{A}$
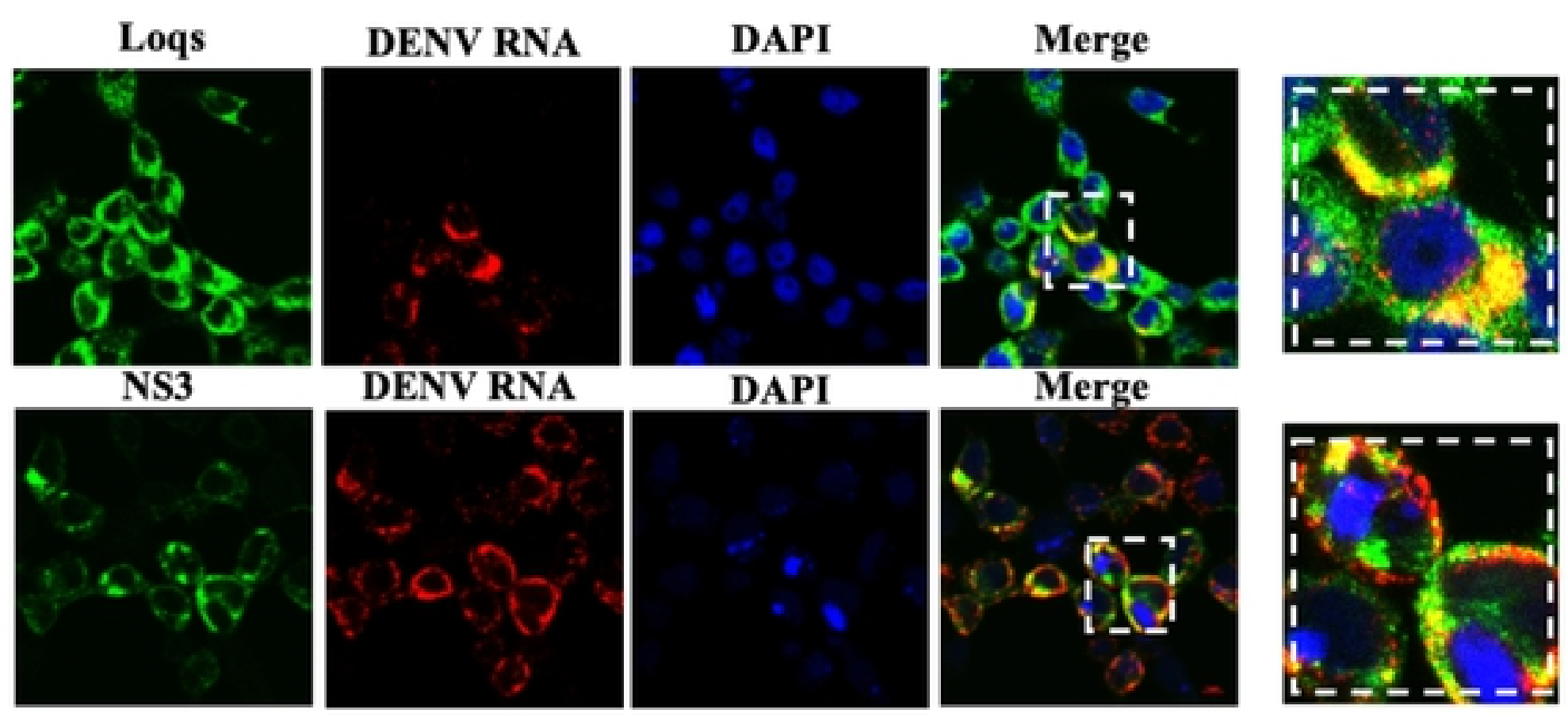

DENV RNA

DAPI

Merge
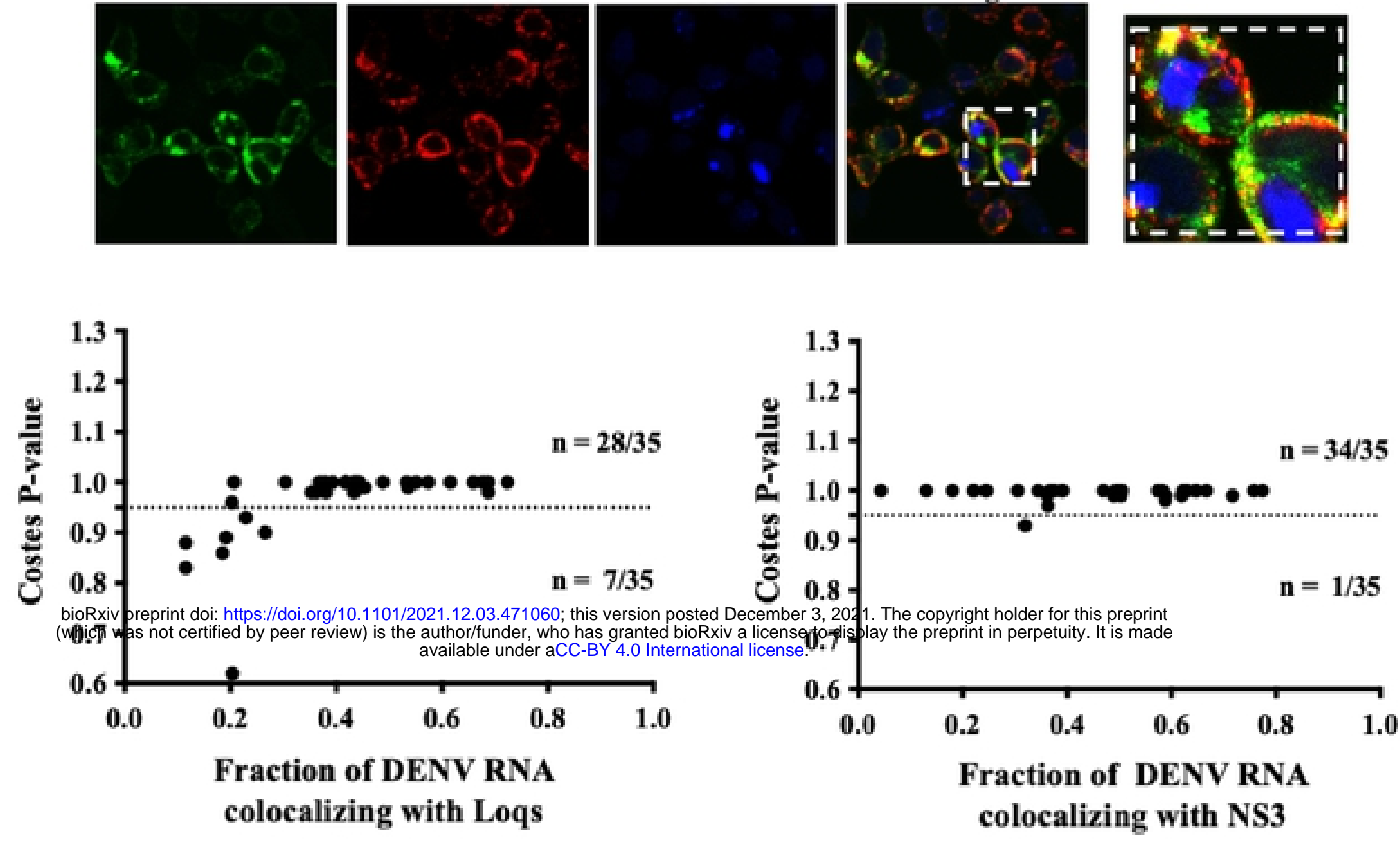

(bich was not certified by peer review) is the author/funder, who has granted bioRxiv a licenselogedis play the preprint in perpetuity. It is made available under aCC-BY 4.0 International license.

Fraction of DENV RNA

colocalizing with Loqs

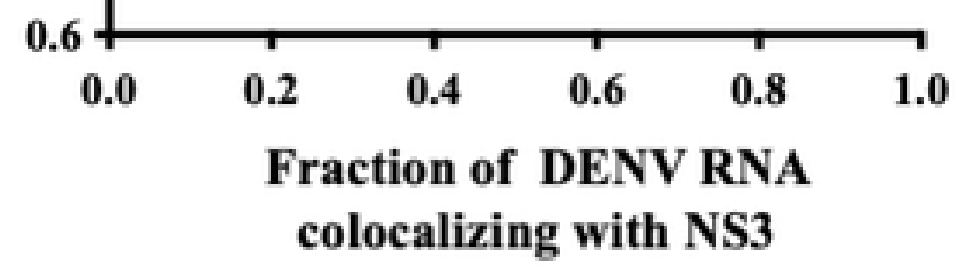

B

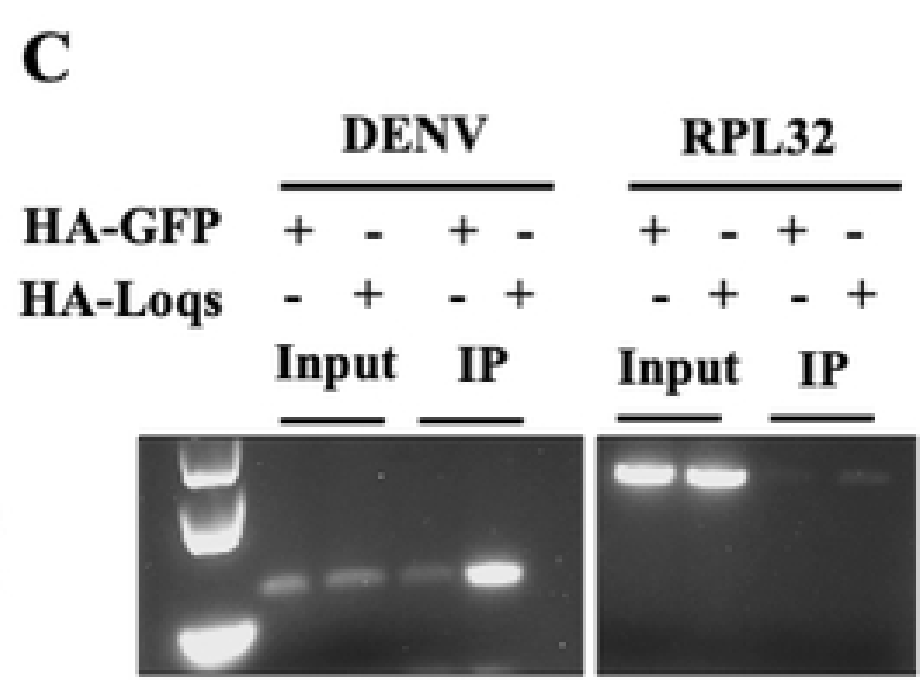

$\begin{array}{llll}\text { HA-GFP + } & - & + & - \\ \text { HA-Loqs - } & + & - & +\end{array}$

$$
\begin{array}{lll}
\text { Input } & & \text { IP } \\
\hline 5 & 5
\end{array}
$$

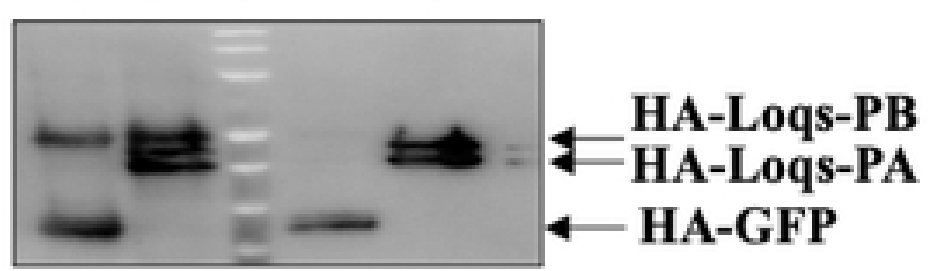

WB: HA

D

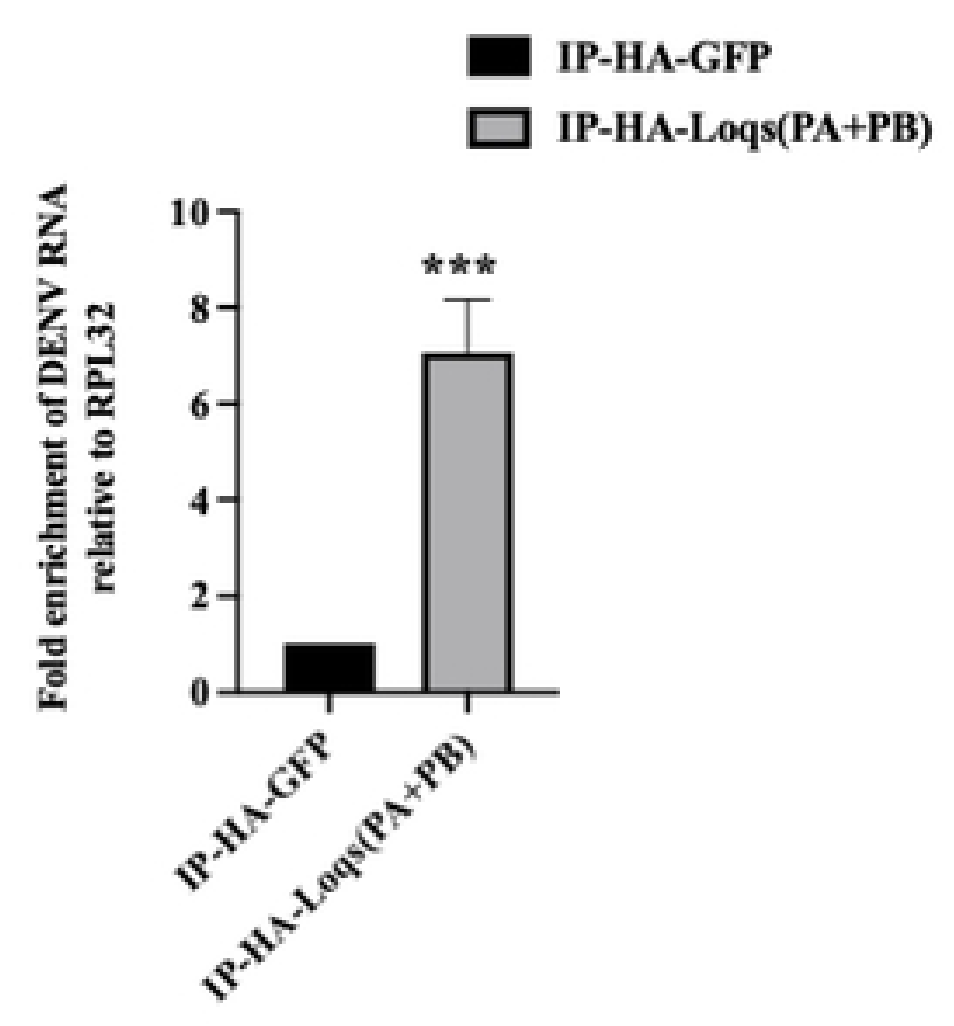

Fig. 4 
$\mathbf{A}$

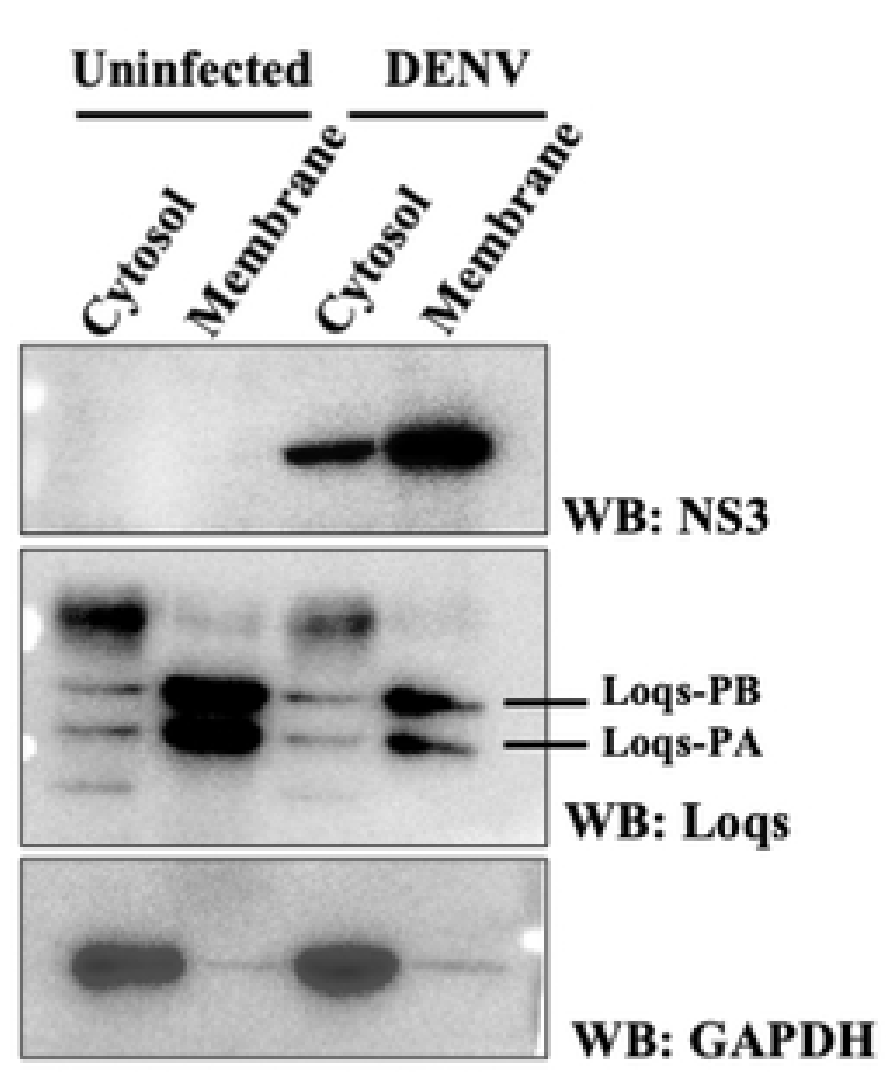

B
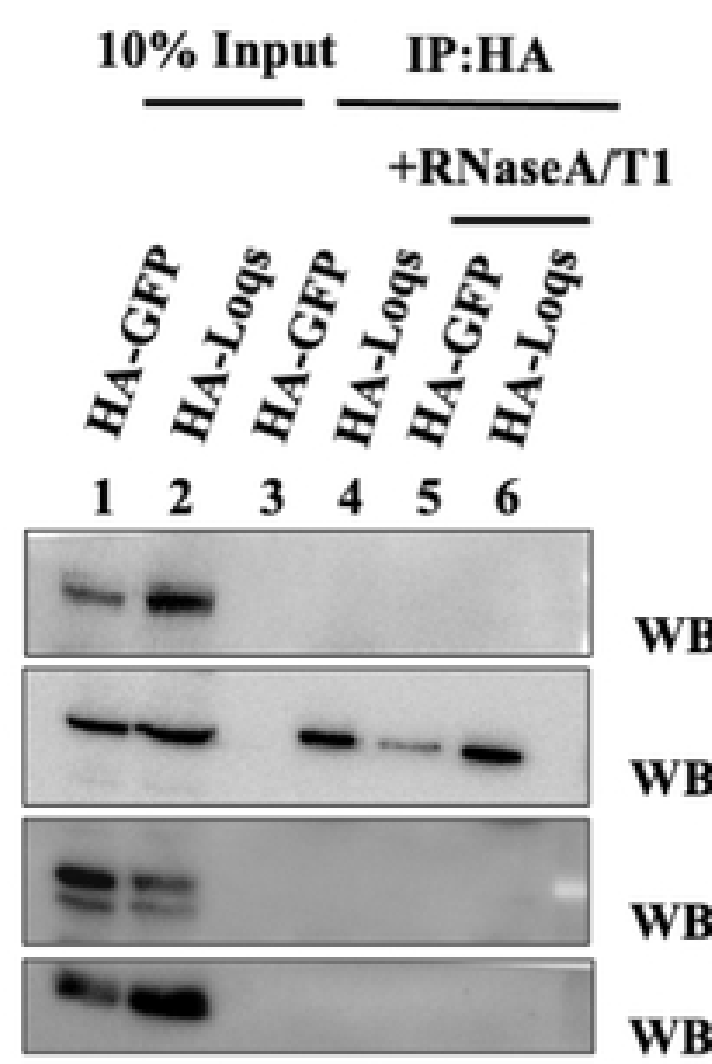

WB: NS5

WB: NS3

WB: NS4B

WB: Capsid

C

\section{Wildtype replicon}

5'UTR

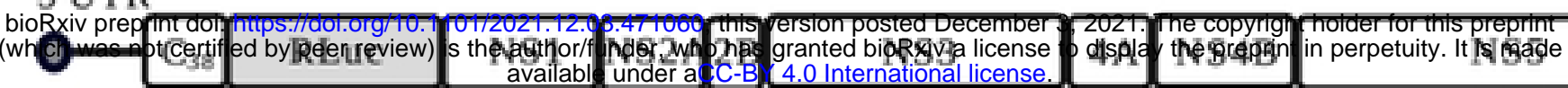

3'UTR
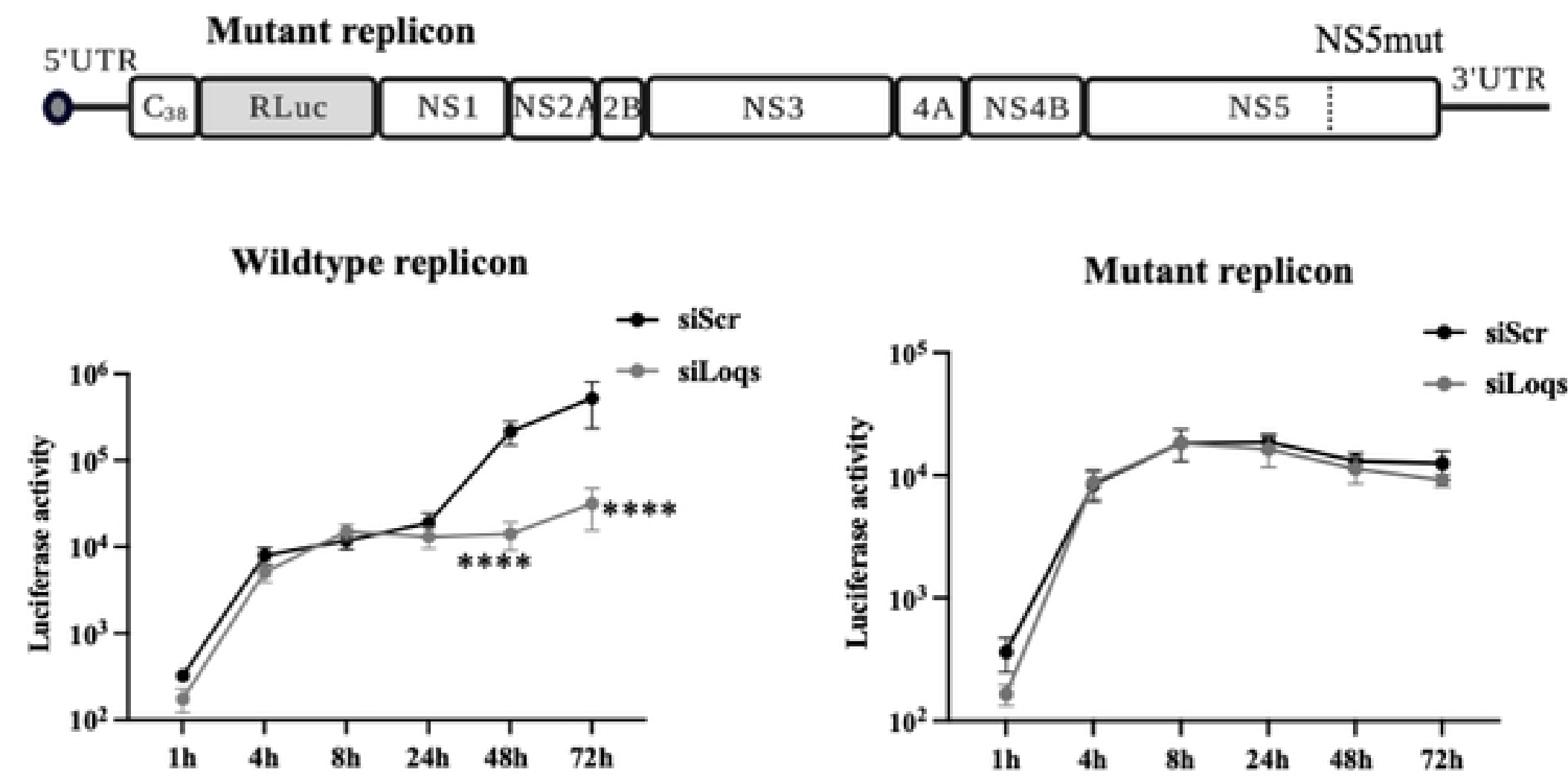

D

..- No drug treatment

$\rightarrow$ siScr+2'CMA

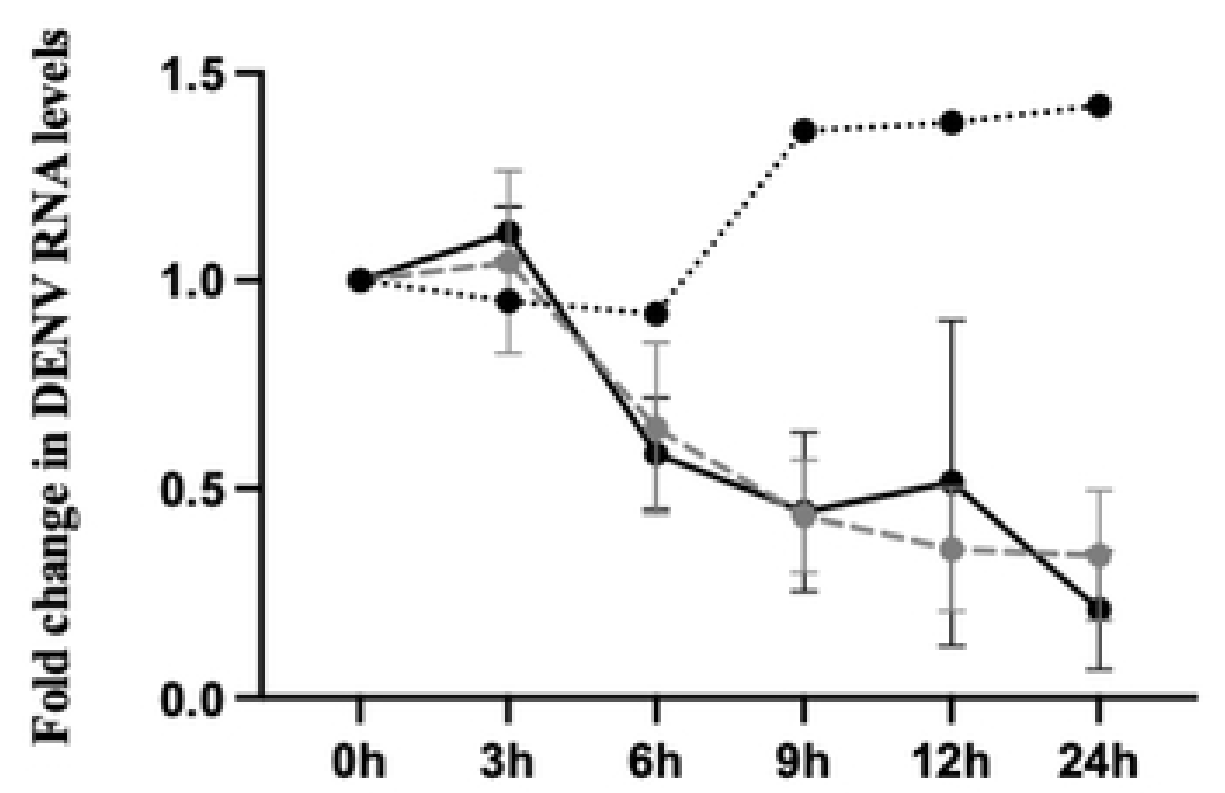

$\rightarrow$ siLoqs+2'CMA

Fig. 5 
Figure S1: Effect of Loqs KD on flaviviral infection

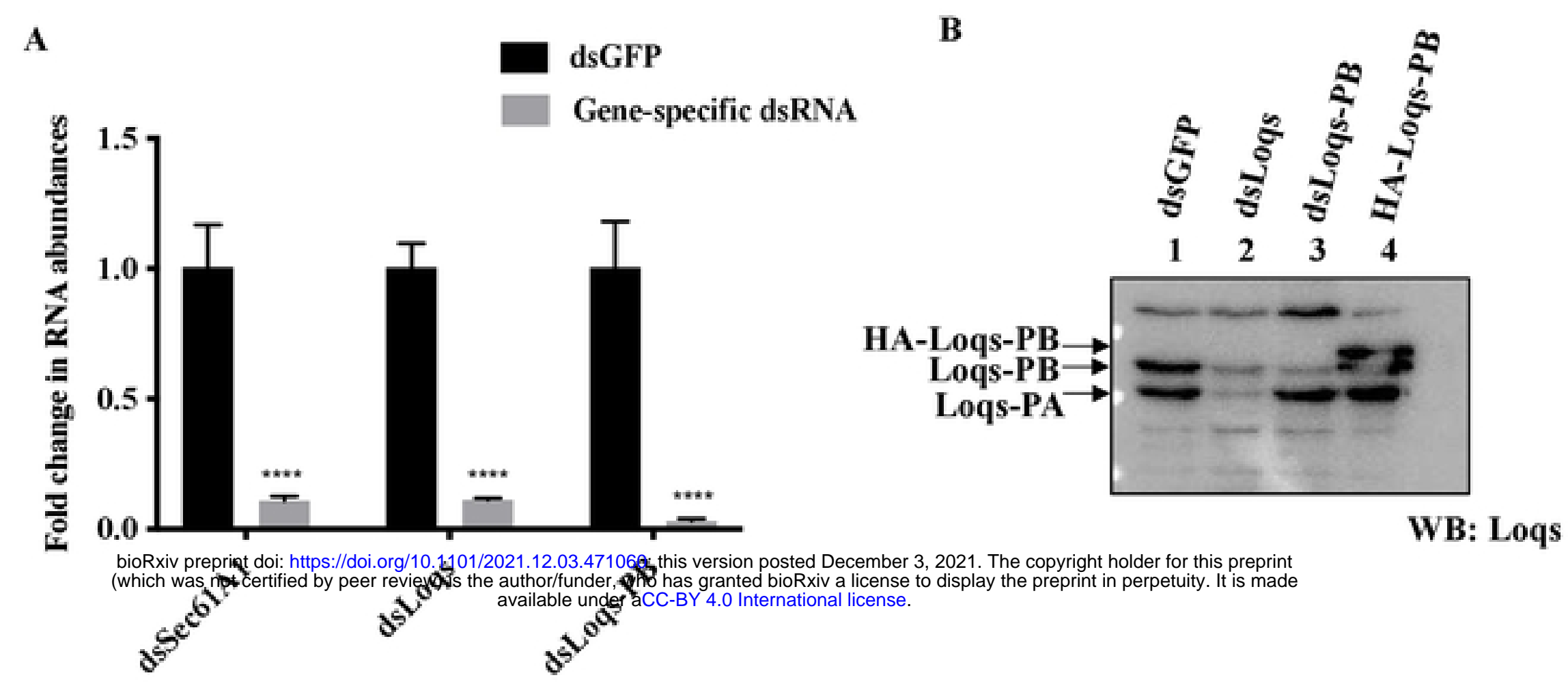

C

DENV2-16681 infection

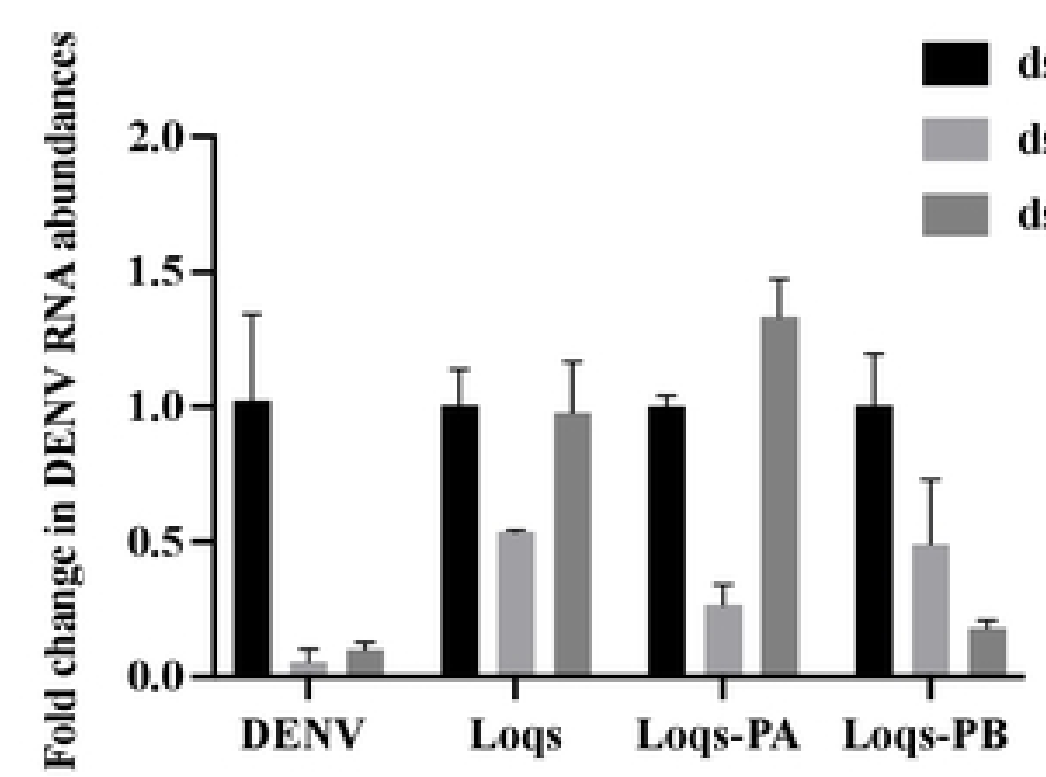

D Viral RNA in cell culture supernatant

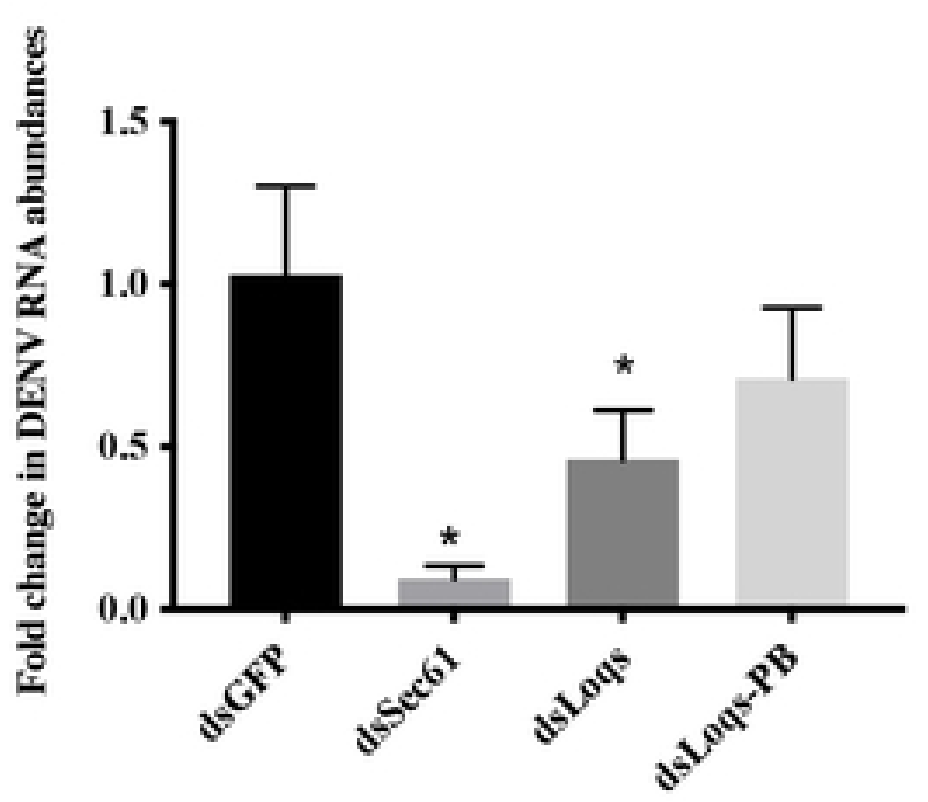

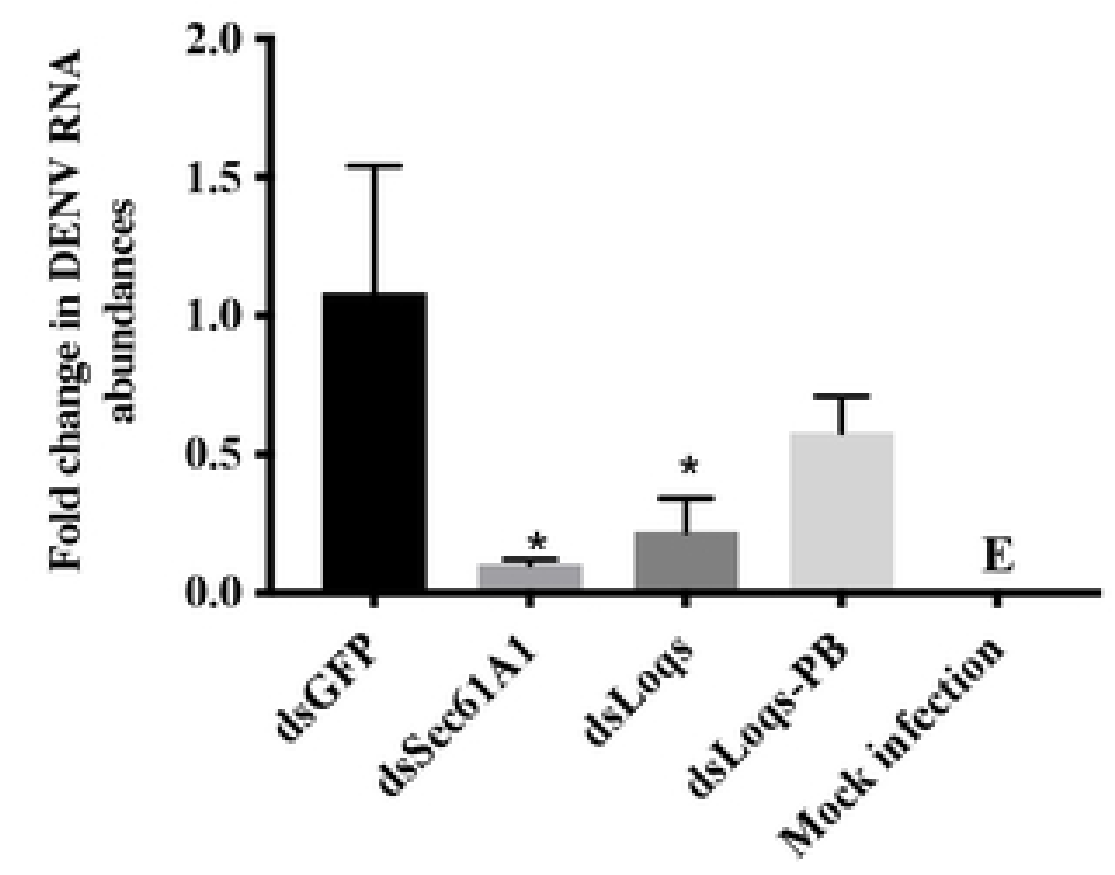


Figure S2: Effect of Loqs over-expression in DENV2-infected Aag2 cells

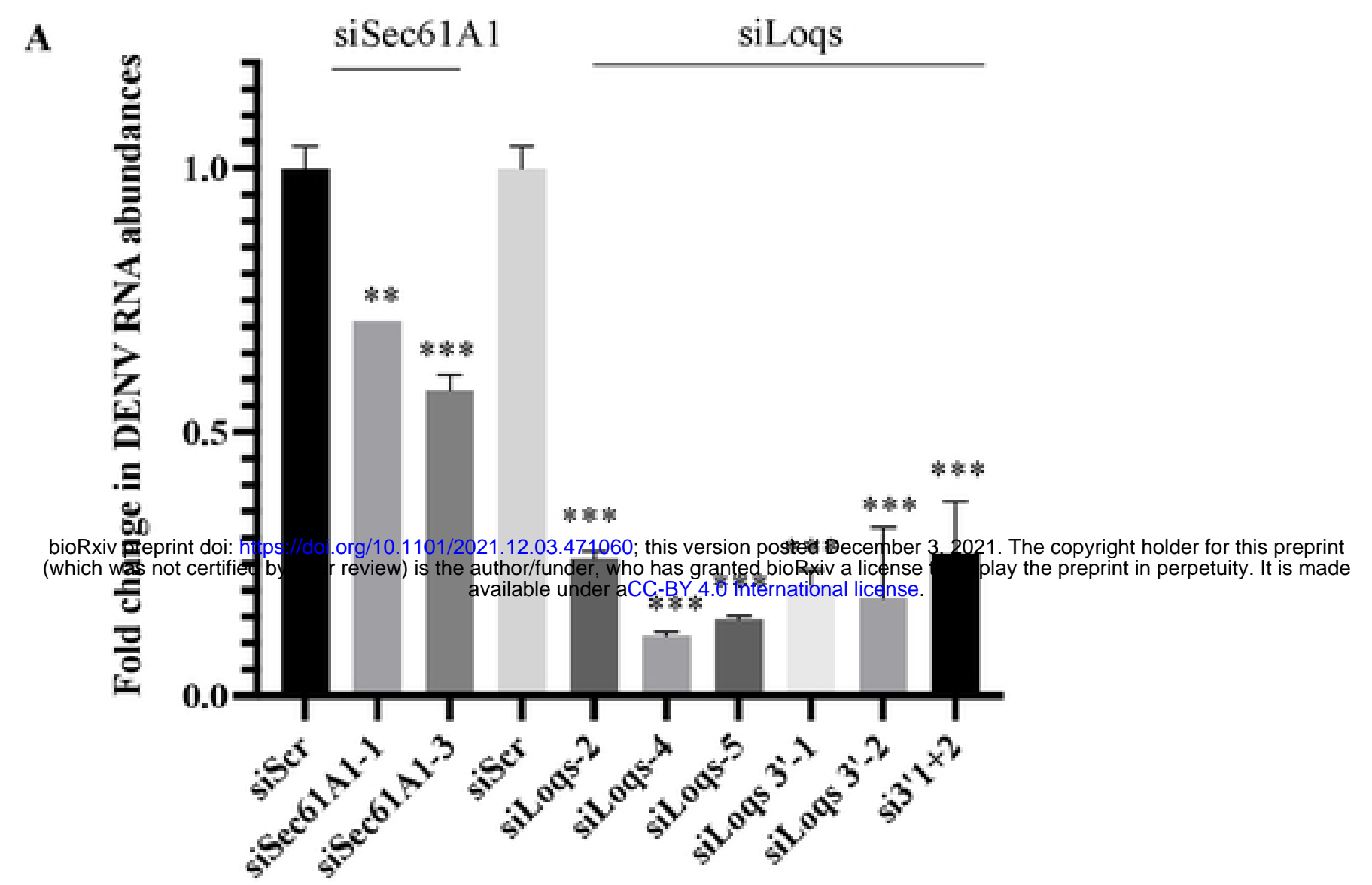

B

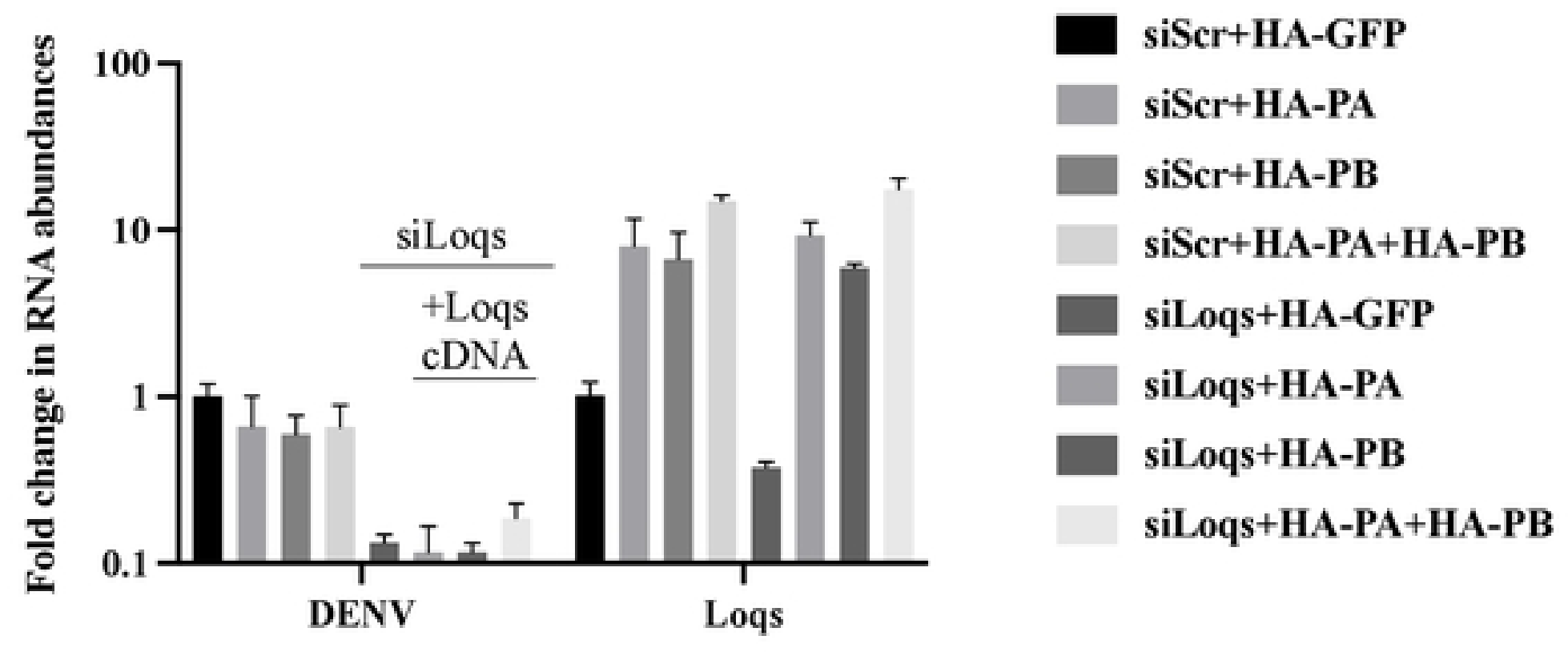


Figure S3: irCLIP of Loqs

A

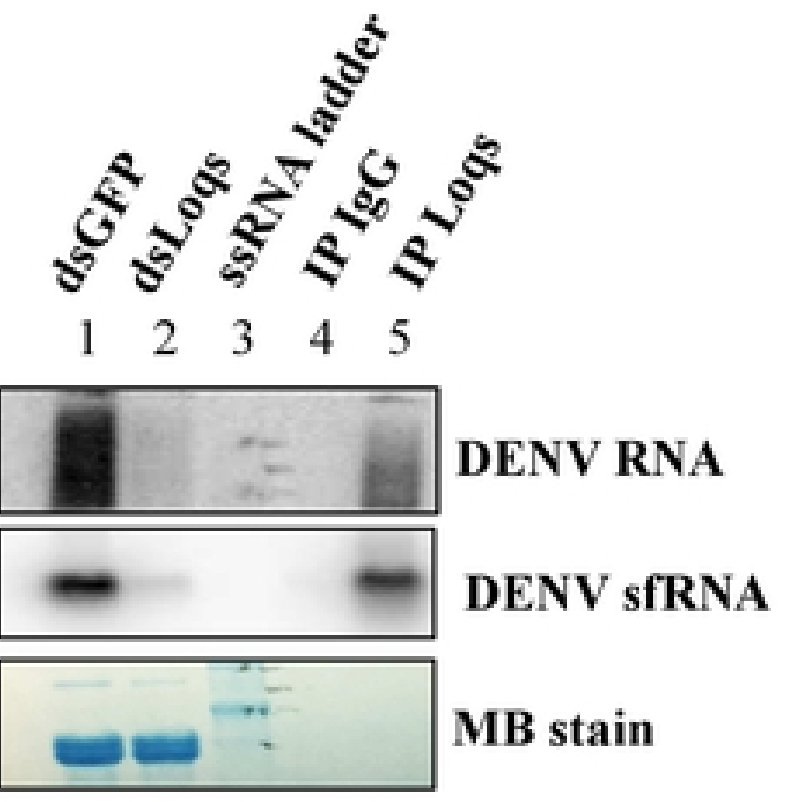

bioRxiv preprint doi: https://doi.org/10.1101/2021.12.03.471060; this version posted December 3, 2021. The copyright holder for this preprint (which was not certified by peer review) is the author/funder, who has granted bioRxiv a license to display the preprint in perpetuity. It is made

B

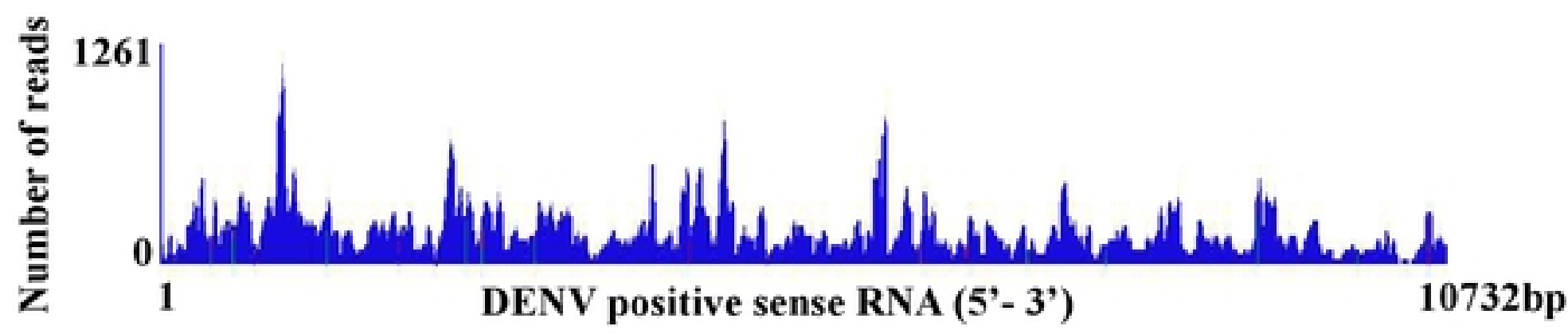

C

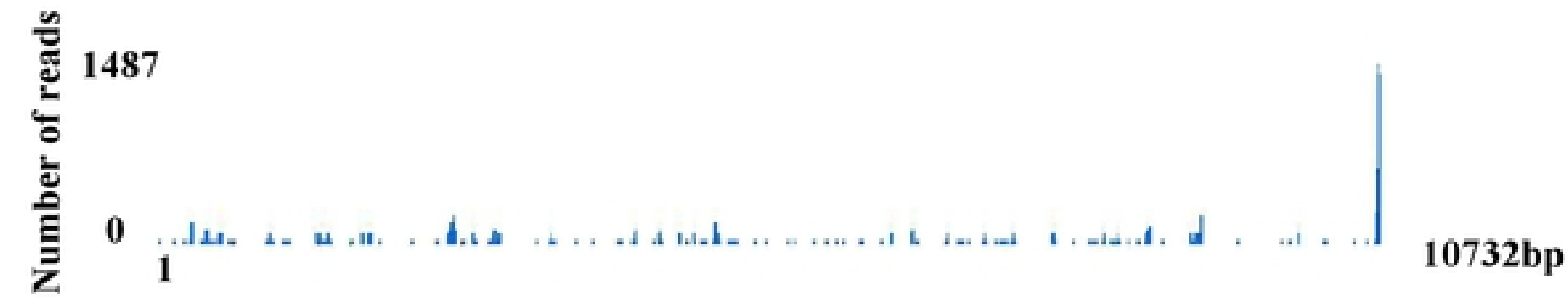

DENV negative sense RNA (5'- 3') 
Figure S4: Effect of Loqs/Sec61A1 KD on polysome association of DENV RNA
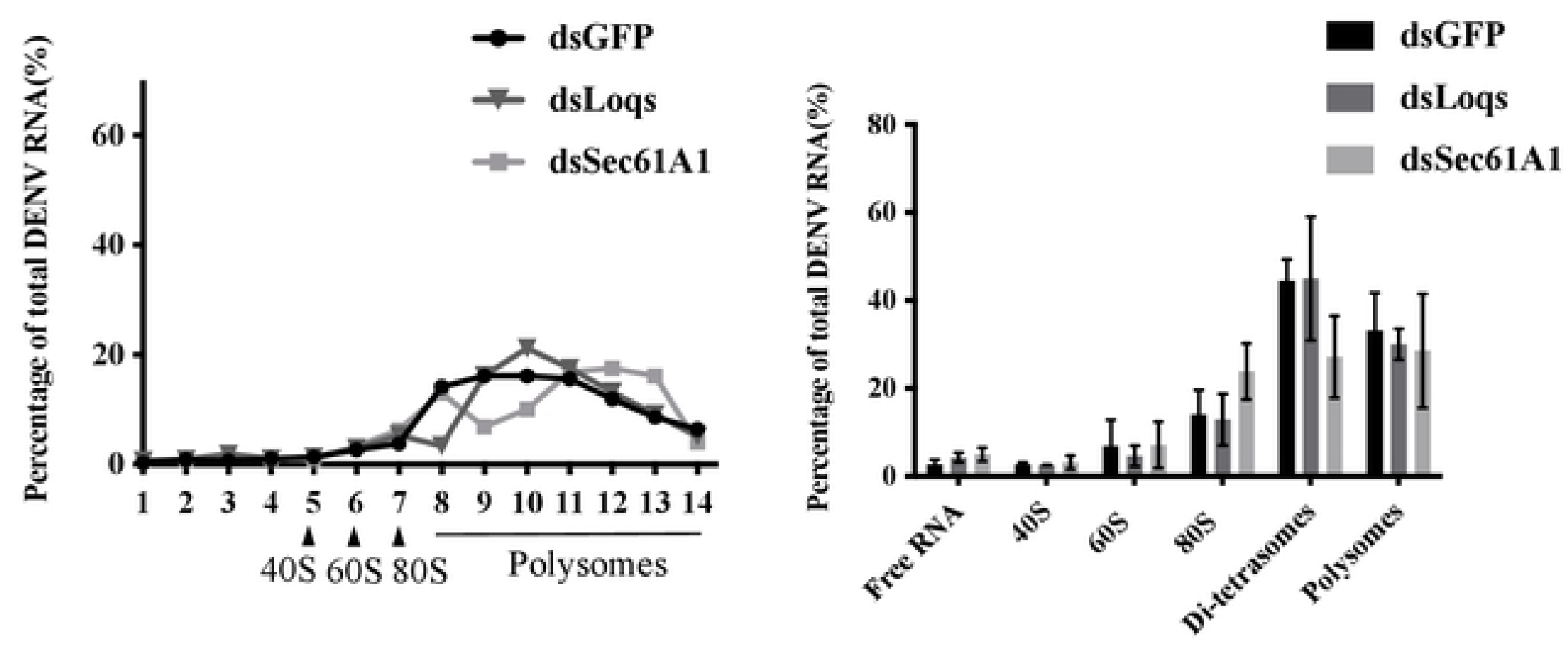

bioRxiv preprint doi: https://doi.org/10.1101/2021.12.03.471060; this version posted December 3, 2021. The copyright holder for this preprint (which was not certified by peer review) is the author/funder, who has granted bioRxiv a license to display the preprint in perpetuity. It is made available under $\mathrm{ACC}-\mathrm{BY} 4.0$ International license. 
Fig S5: Effect of Dicer KD on Loqs inhibition of DENV replication

A Infectious, full-length DENV2 RNA

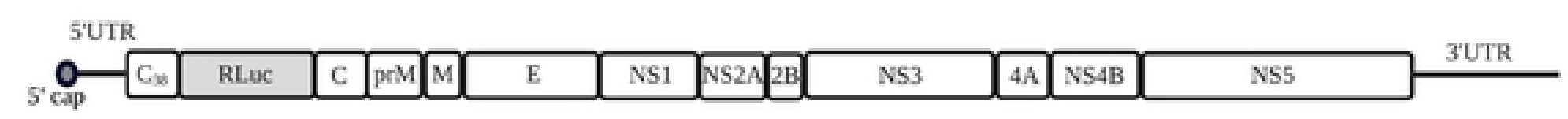

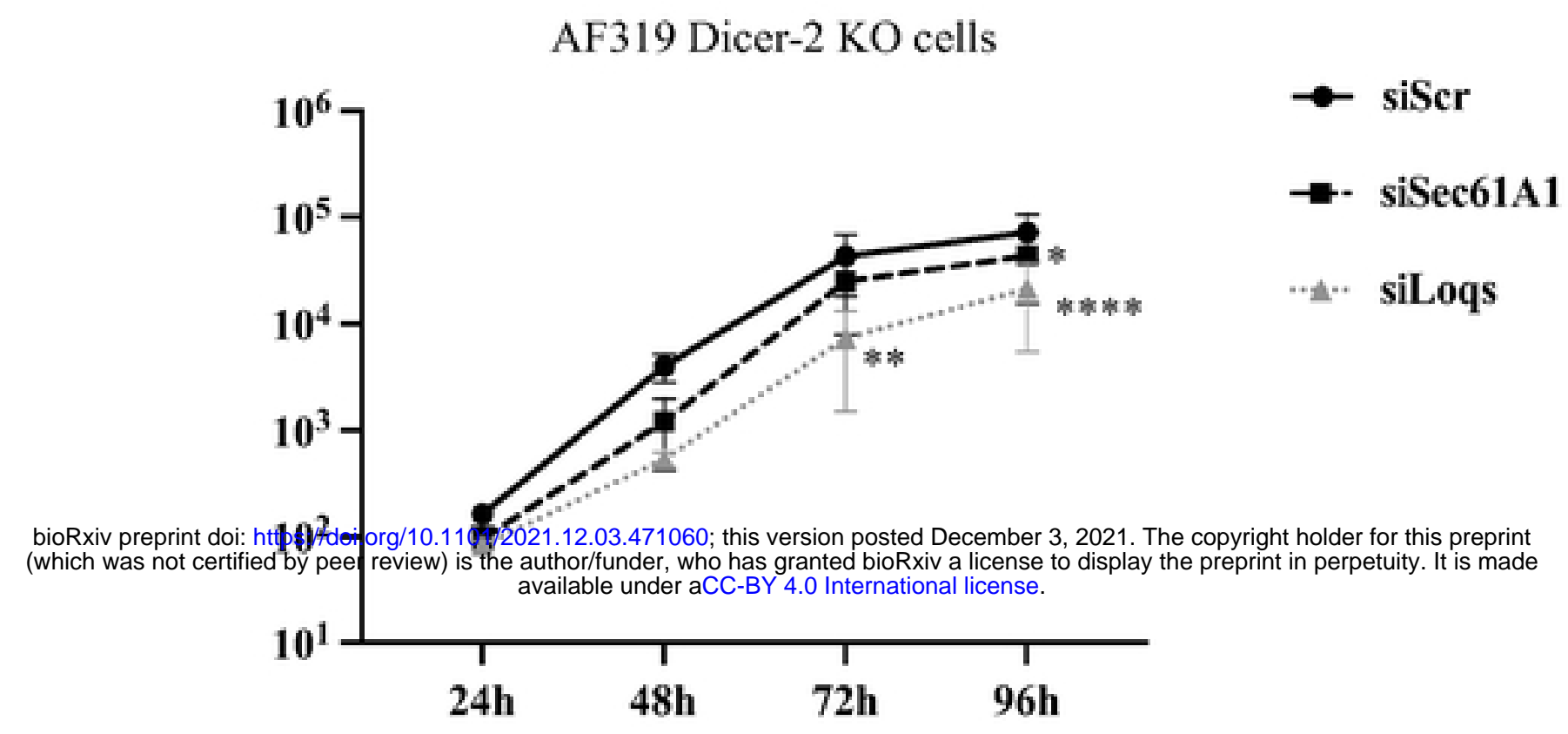

\begin{tabular}{|c|c|c|c|c|c|c|c|}
\hline $0-C_{3}$ & RLuc & NS1 & $\mathrm{NS} 2 \mathrm{~A} 2 \mathrm{~B}$ & NS3 & $4 \mathrm{~A}$ & NS4B & NS5 \\
\hline
\end{tabular}

AF319 Dicer-2 KO cells

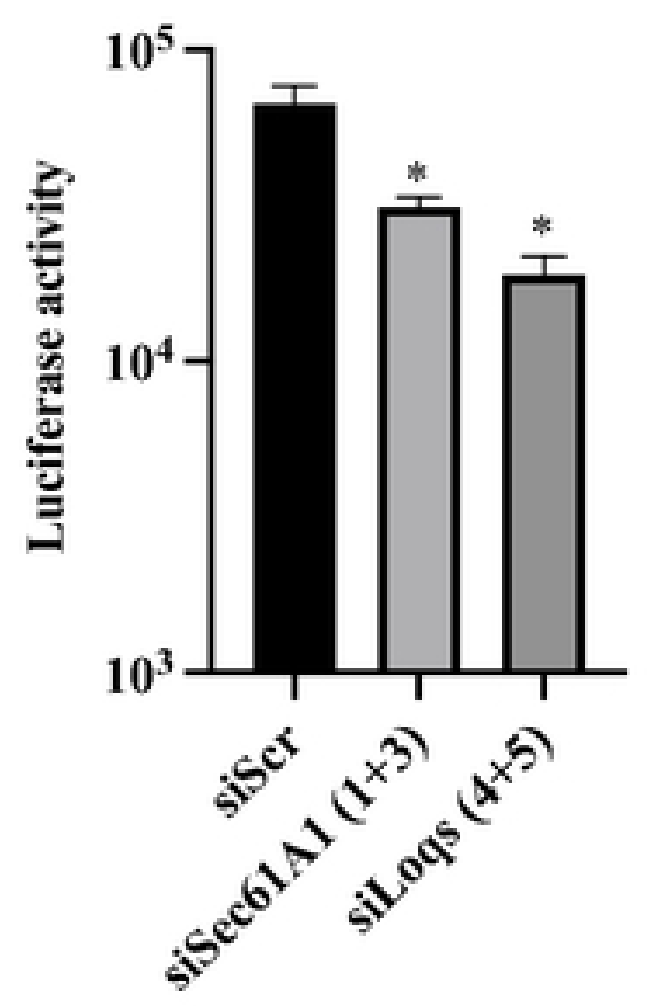

